Supporting Information For:

\title{
A Toxic RNA Templates the Synthesis of its own Fluorogenic Inhibitor by Using a Bioorthogonal Tetrazine Ligation in Cells and Tissues
}

\author{
Alicia J. Angelbello 1 and Matthew D. Disney ${ }^{*}{ }_{1}$ \\ 1 Department of Chemistry, The Scripps Research Institute, 130 Scripps Way, Jupiter, FL 33458 \\ USA \\ *author to whom correspondence should be addressed: \\ Email: Disney@scripps.edu \\ Phone: 561-228-2203 \\ Fax: 561-228-2147
}

Figures $\mathrm{S} 1-\mathrm{S} 15$

Experimental Methods

Synthetic Methods 
A

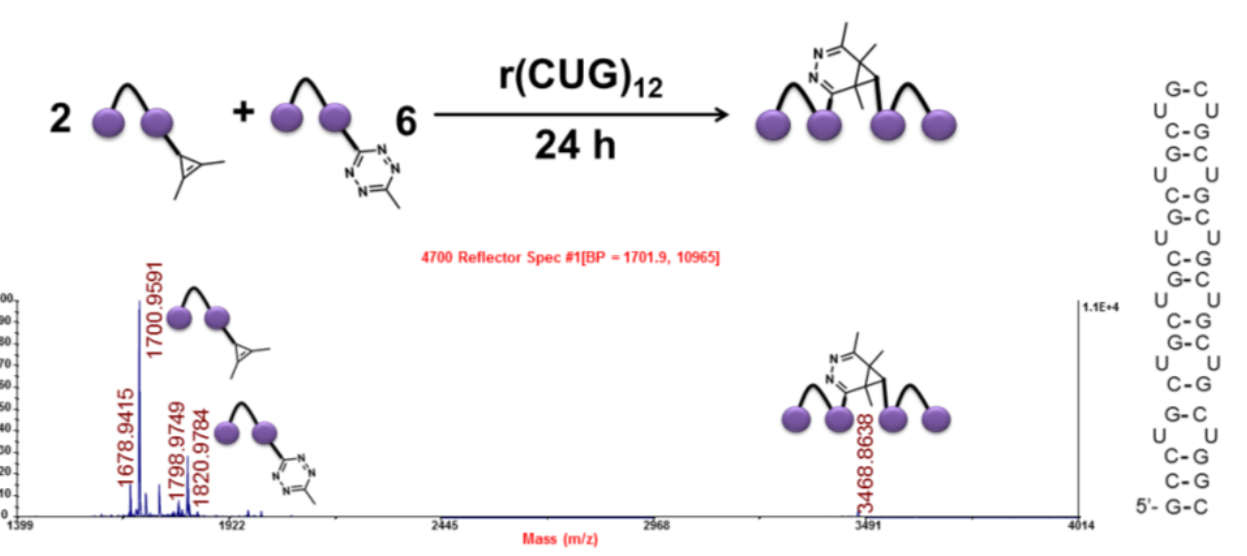

B
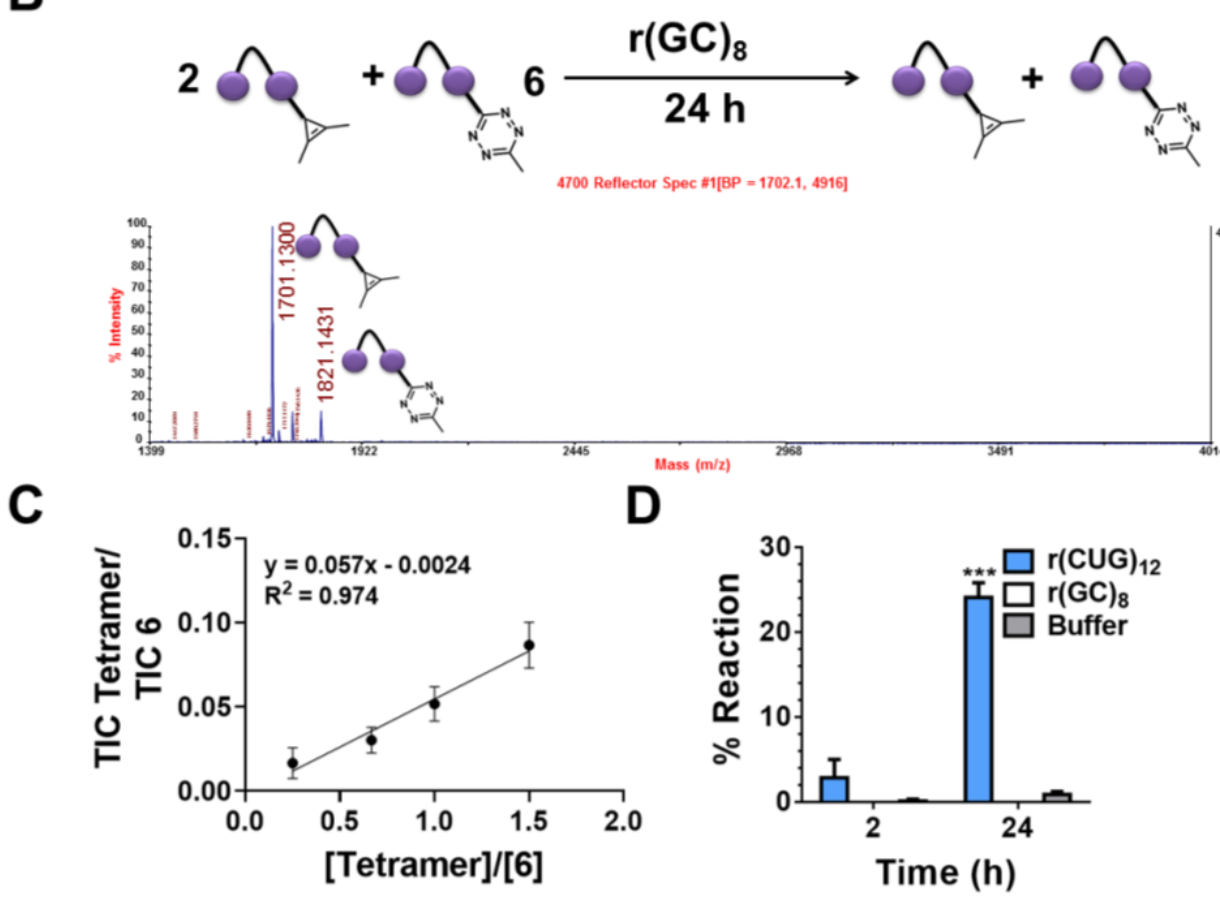

D

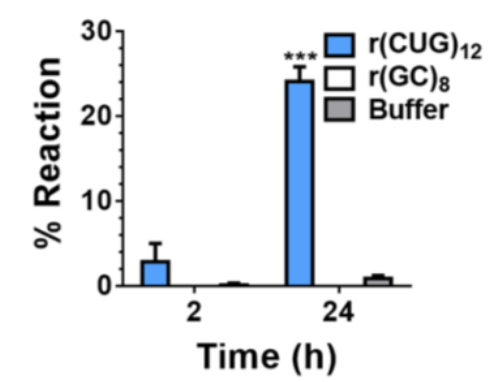

Figure S1. In vitro (CUG) repeat-templated tetrazine ligation. (A) Representative mass spectrum of reaction of $\mathbf{2}$ and $\mathbf{6}$ in the presence of $r(C U G){ }_{12}$. (B) Representative mass spectrum of $\mathbf{2}$ and $\mathbf{6}$ in the presence of $r(\mathrm{GC})_{8}$. (C) Standard curve used to extrapolate reaction products. The standard curve was generated by taking the ratio of the total ion count (TIC) of tetramer product to the total ion count (TIC) of starting material 6 when the two compounds were mixed at different concentrations. (D) Quantification of reaction of $2 \& \mathbf{6}$ in the presence of $r(C U G)_{12}, r(G C)_{8}$, and buffer $(\mathrm{n}=3)$. Error bars represent $\mathrm{SD} ;{ }^{* * *} P<0.001$, one-way ANOVA relative to samples in buffer. 


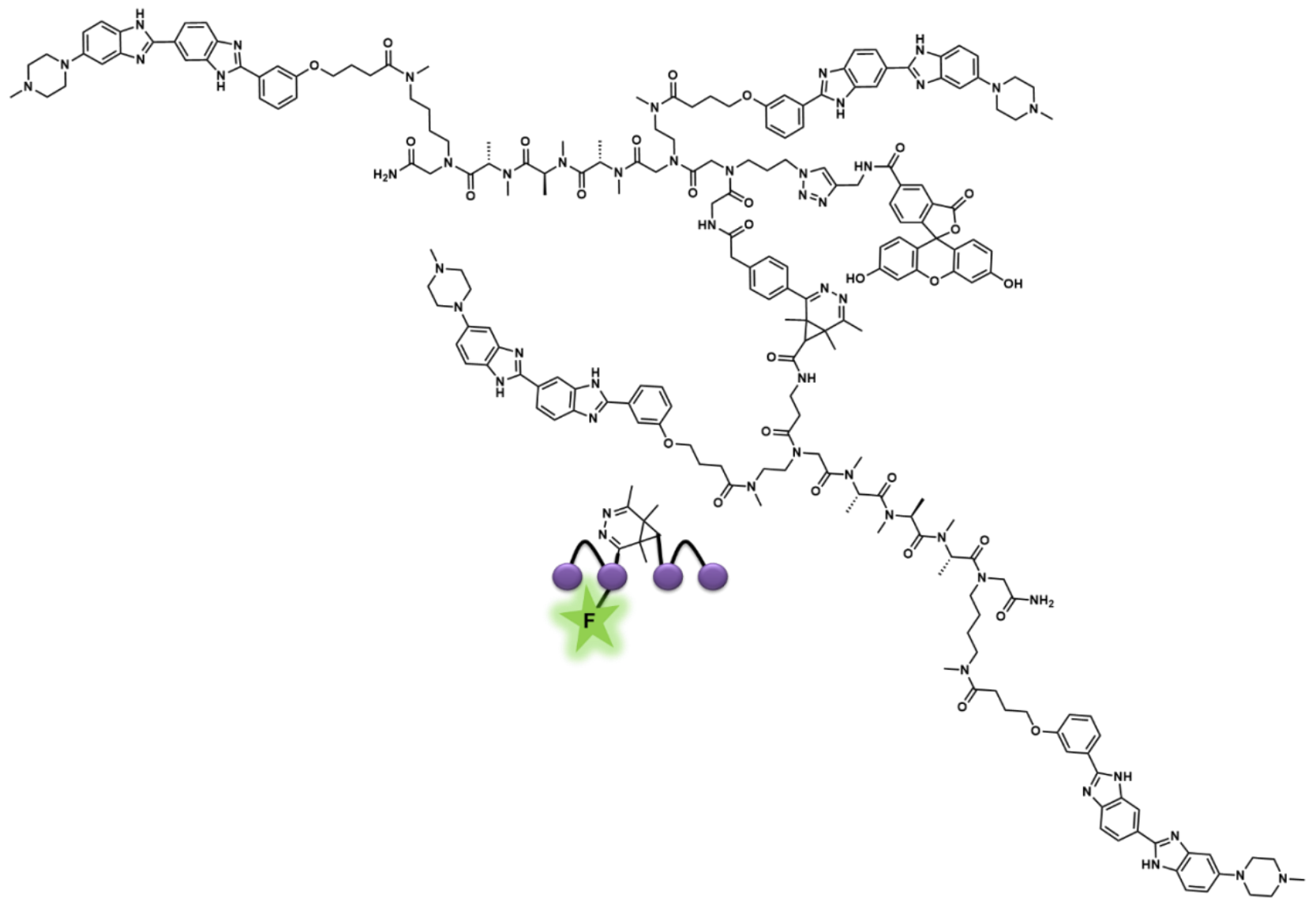

Figure S2. Structure of product formed between $\mathbf{6}$ and $\mathbf{8}$ in the presence of $r(C U G)$ exp. 
A

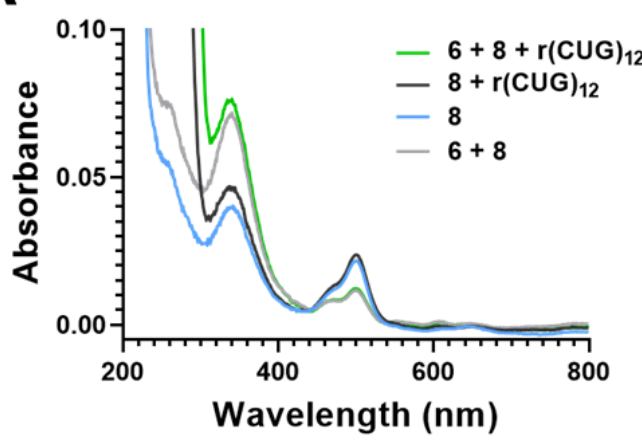

B

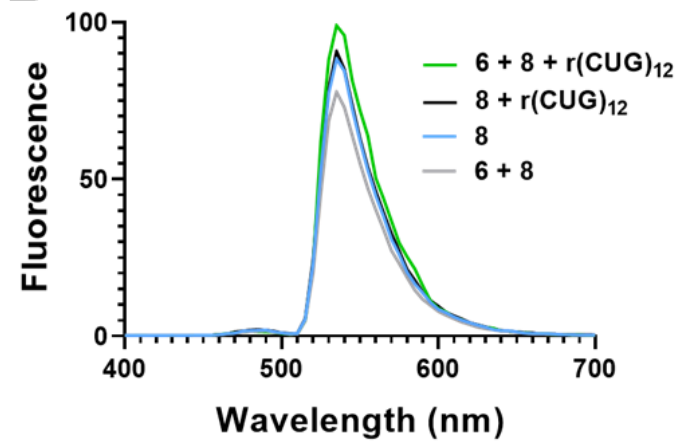

Figure S3. Absorbance and fluorescence spectra of fluorogenic tetrazine ligation. (A) Absorbance spectra of 8 alone, 8 with r(CUG) $12,8+\mathbf{6}$ only, and $8+\mathbf{6}$ with r(CUG)12 after $24 \mathrm{~h}$. (B) Fluorescence spectra of $\mathbf{8}$ alone, 8 with $r(C U G) 12,8+6$, only and $\mathbf{8}+\mathbf{6}$ with $r(C U G) 12$ after $24 \mathrm{~h}$. 


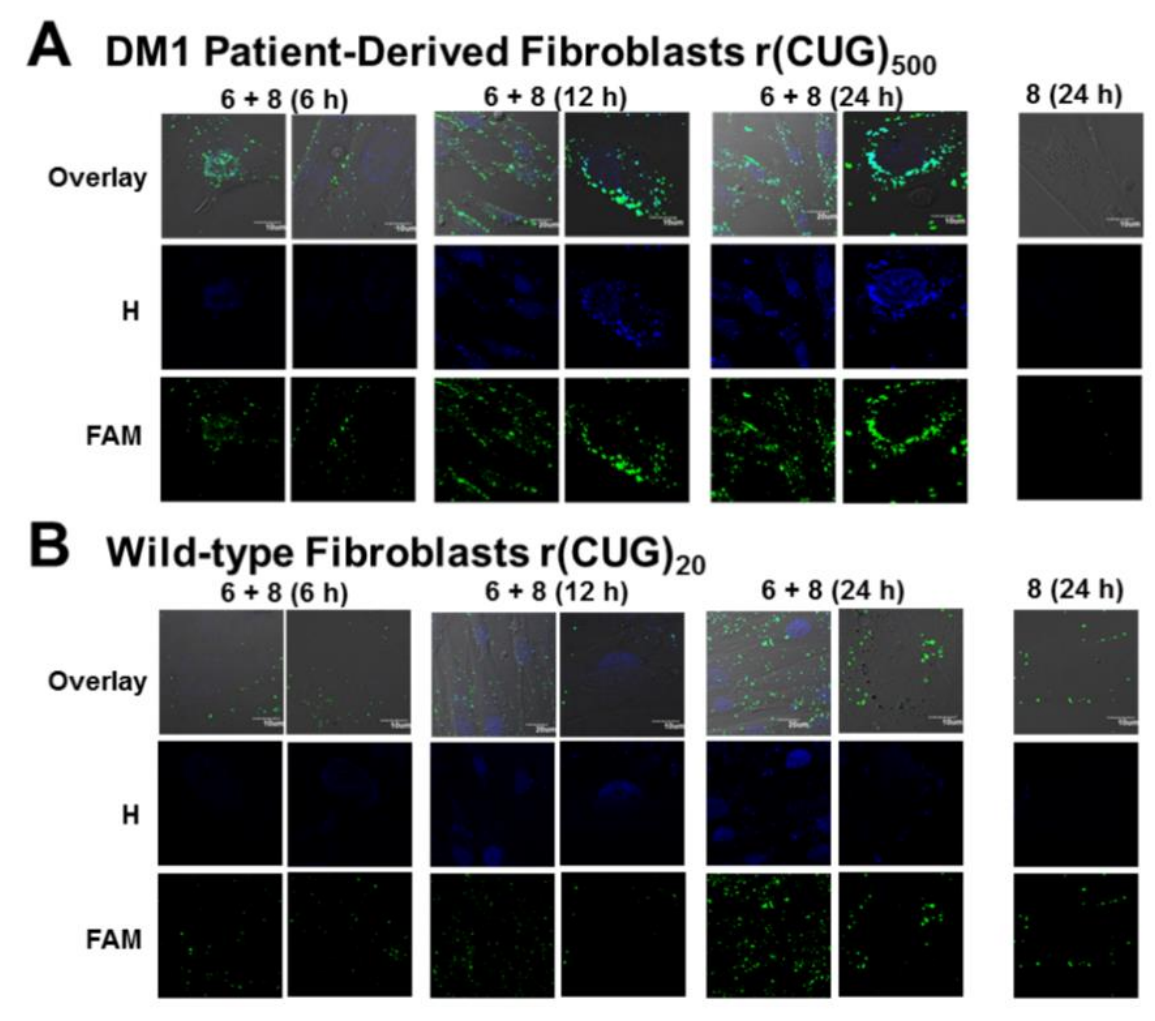

Figure S4. In cellulis r(CUG) exp-templated fluorogenic tetrazine ligation. (A) Representative livecell images of DM1 patient-derived fibroblasts [r(CUG)500] treated with $\mathbf{6}$ and $\mathbf{8}$ or $\mathbf{8}$ alone, imaged as a function of time post-treatment. (B) Representative live-cell images of wild-type fibroblasts $\left[r(C \cup G)_{20}\right]$ treated with $\mathbf{6}$ and $\mathbf{8}$ or $\mathbf{8}$ alone, imaged as a function of time post-treatment. 


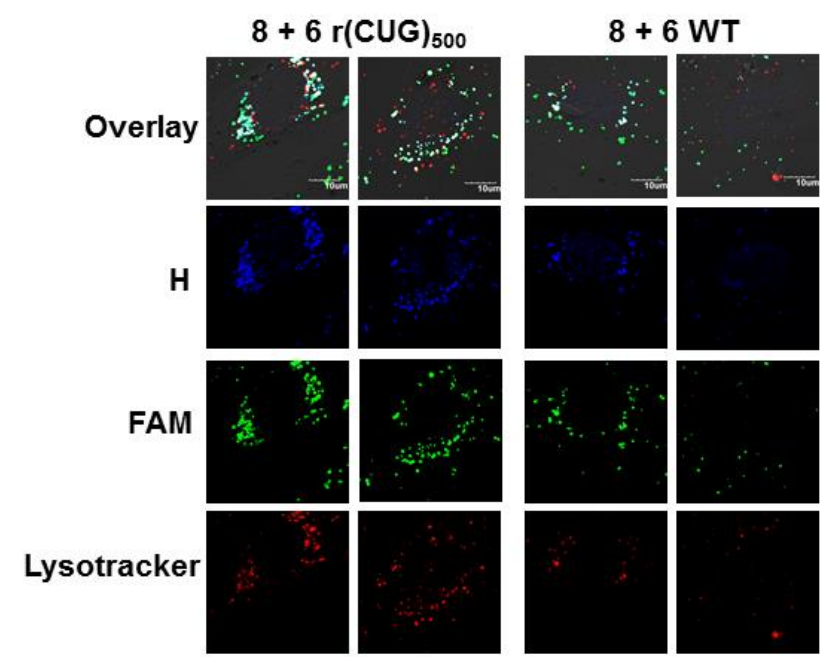

Figure S5. Representative live-cell images of DM1 patient-derived and wild-type fibroblasts treated with $\mathbf{6}$ and $\mathbf{8}$ and stained with Lysotracker, showing that the tetramer product formed is localized in the lysosome. 

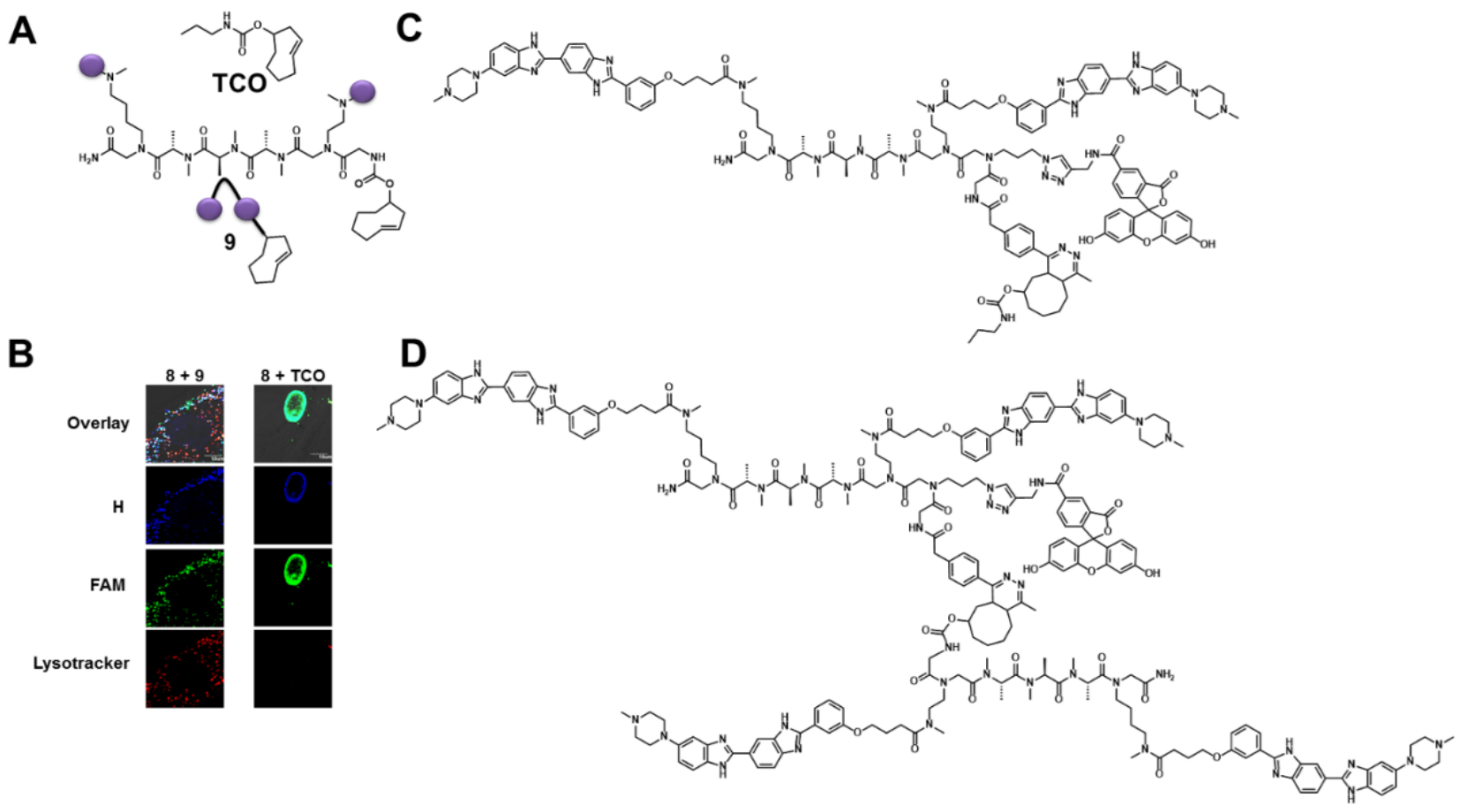

Figure S6. Tetrazine reaction with trans-cyclooctene (TCO)-containing compounds to probe trafficking to the lysosome. (A) Structures of TCO and a dimer containing TCO (9). (B) Representative live-cell images of $\mathrm{r}(\mathrm{CUG})_{500}$ fibroblasts treated with 8 for $12 \mathrm{~h}$ and then washed and treated with either 9 (traffics to the lysosome upon tetramer formation) or TCO. (C) Structure of the product formed from reaction of 8 with TCO. (D) Structure of the product formed from reaction of 8 with 9 . 

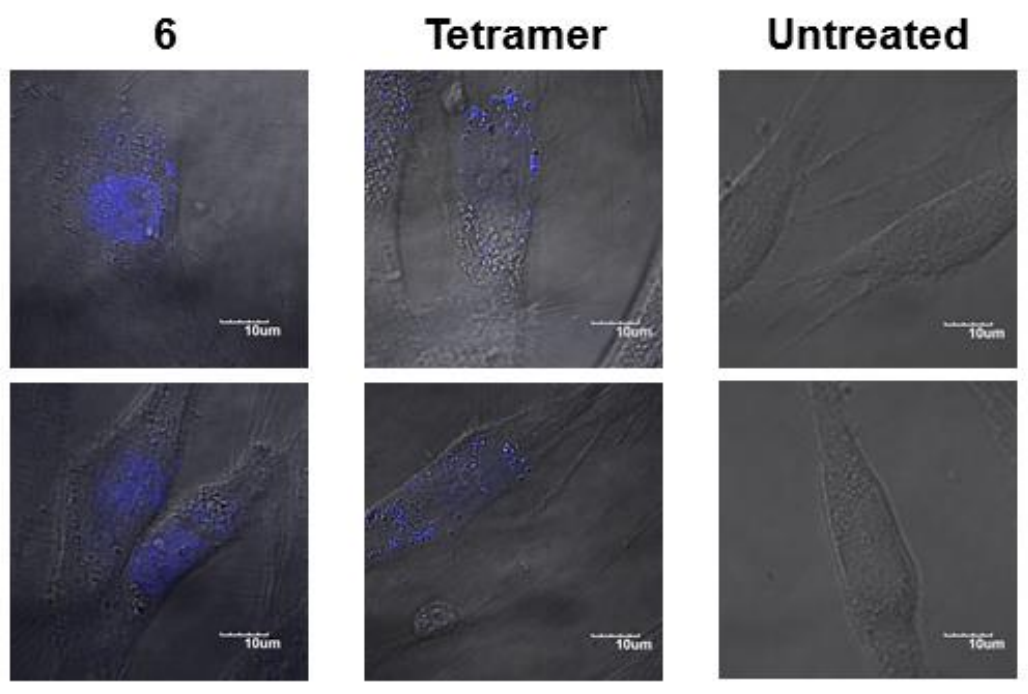

Figure S7. Live-cell imaging of DM1 patient-derived fibroblasts treated with $1 \mu \mathrm{M}$ each of 6 or the tetramer product formed between $\mathbf{2}$ and $\mathbf{6}$. In particular, $\mathbf{6}$ localizes in the nucleus while, in contrast, the tetramer is less cell permeable and only localizes to the cytoplasm. Images are overlays of DIC images and intrinsic fluorescence of $\mathbf{6}$ and the tetramer. 


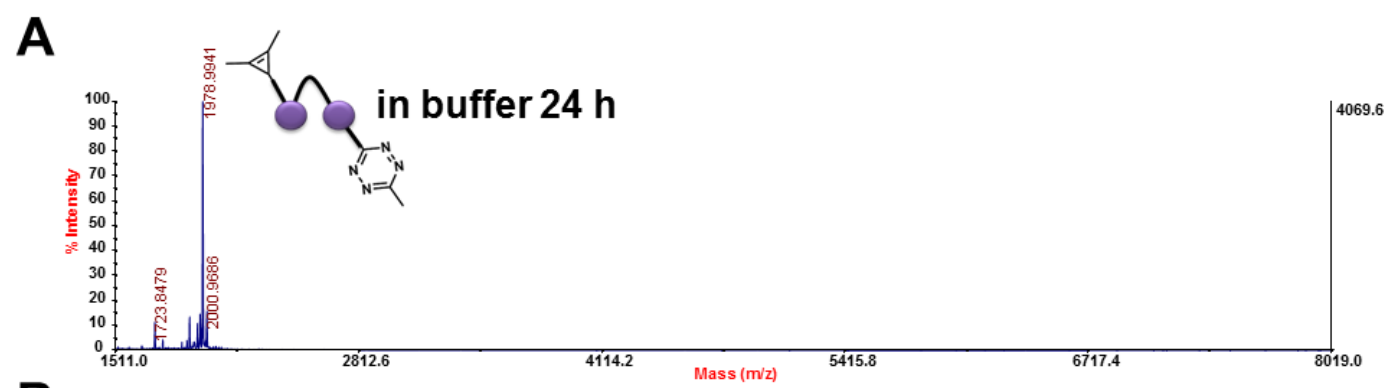

B

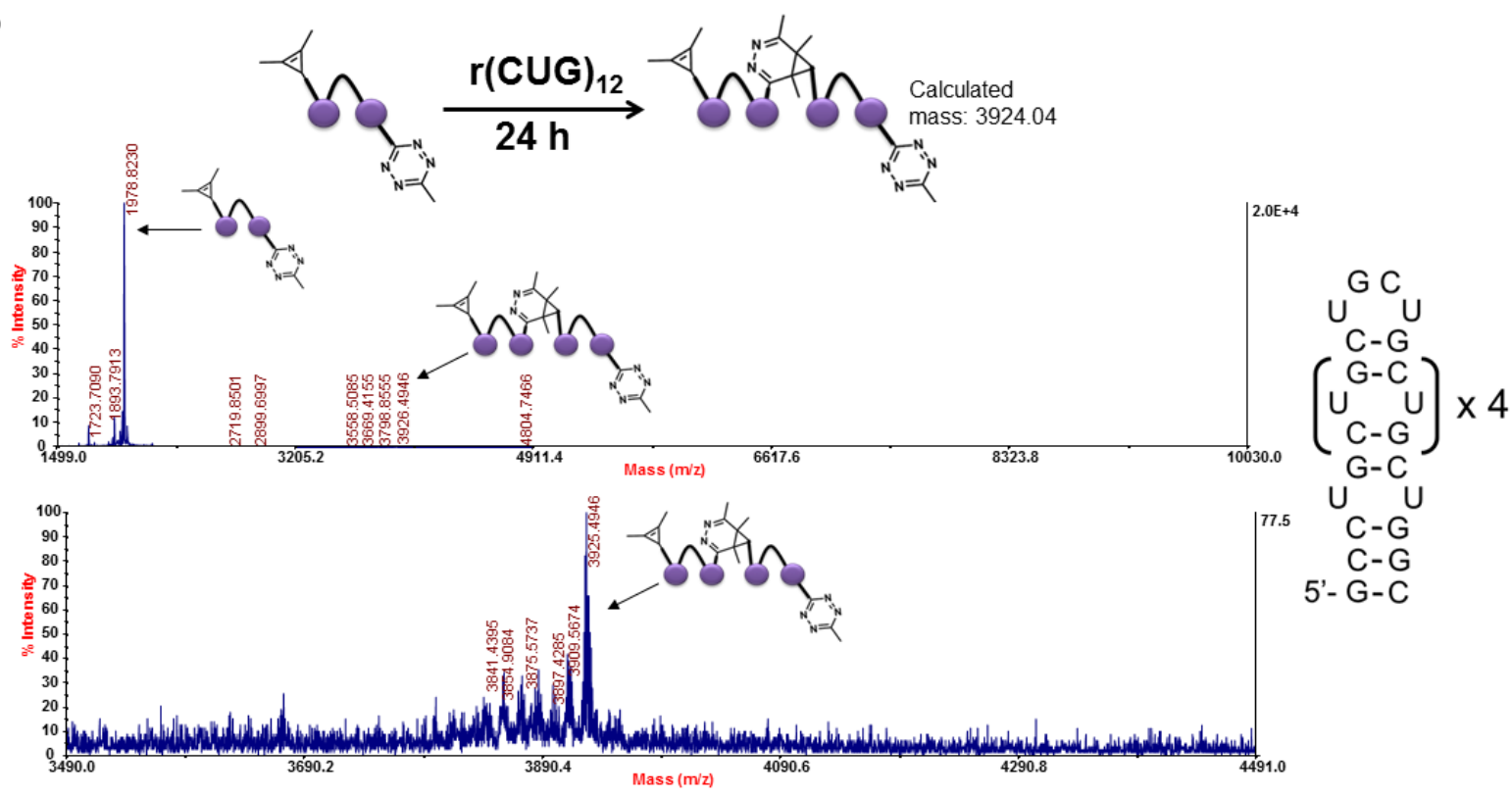

Figure S8. Reaction of $\mathbf{7}$ in the presence of $r(C U G){ }_{12}$. (A) Representative mass spectrum of $\mathbf{7}$ in buffer over $24 \mathrm{~h}$ where no reaction is observed. (B) Representative mass spectra of $\mathbf{7}$ in the presence of $r(C U G) 12$ after $24 \mathrm{~h}$ where a product corresponding to dimerization is observed. Top $=$ full spectrum; bottom $=$ zoom . 

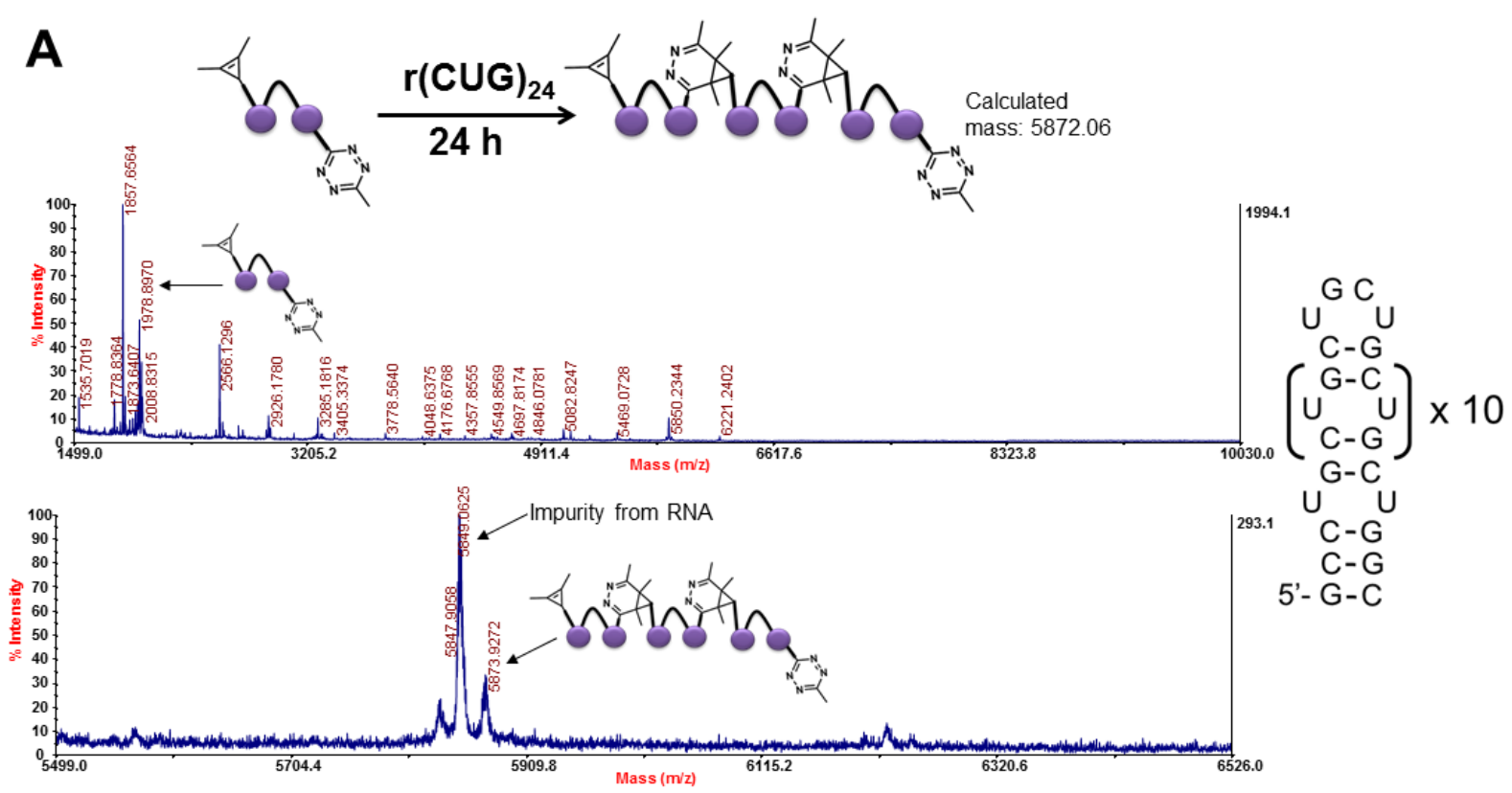

\section{B r(CUG) ${ }_{24}$ alone}

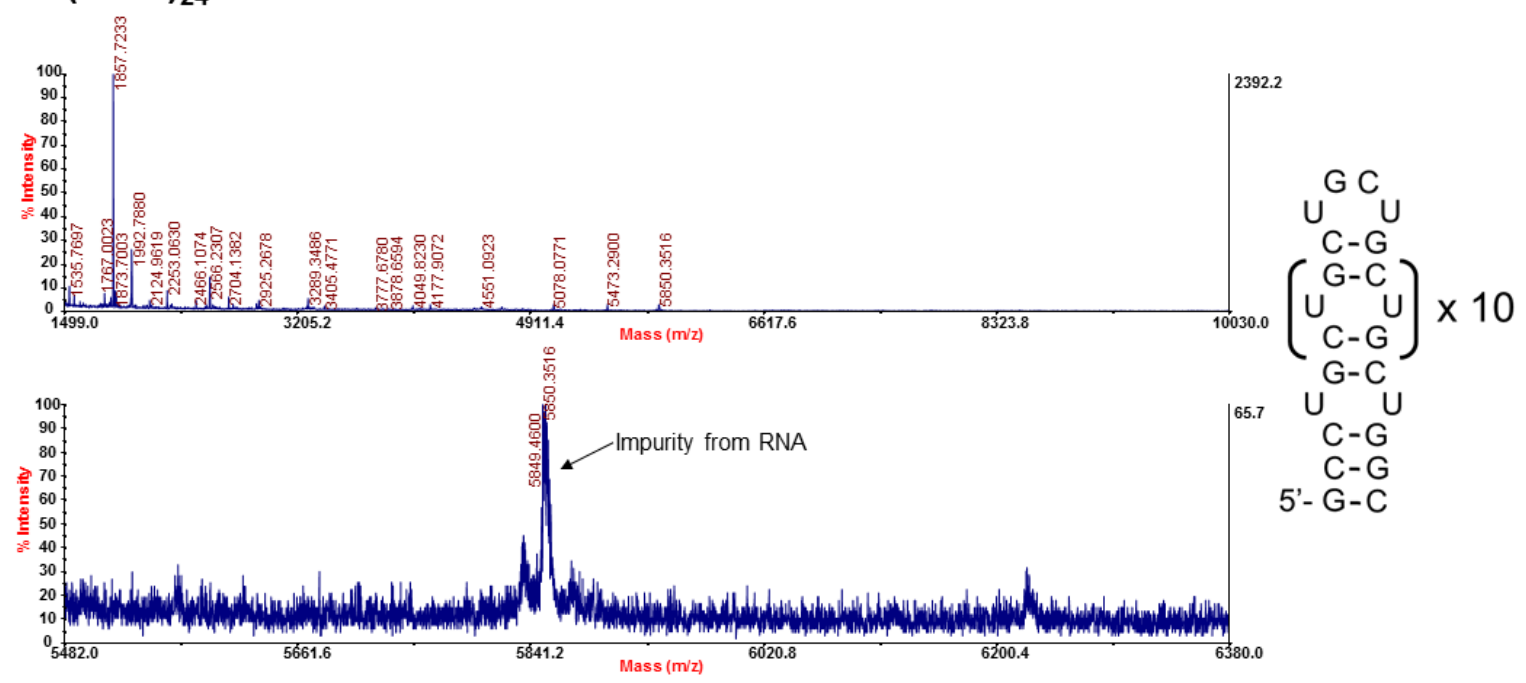

Figure S9. Reaction of $\mathbf{7}$ in the presence of $r(C U G) 24$. (A) Representative mass spectra of $\mathbf{7}$ in the presence of $r(C U G) 24$ after $24 \mathrm{~h}$ where a product corresponding to trimerization is observed. Top $=$ full spectrum; bottom $=$ zoom. (B) Representative mass spectra of $r(C U G)_{24}$ in buffer showing impurities that come from the RNA alone after sample preparation. Top = full spectrum; bottom $=$ zoom . 


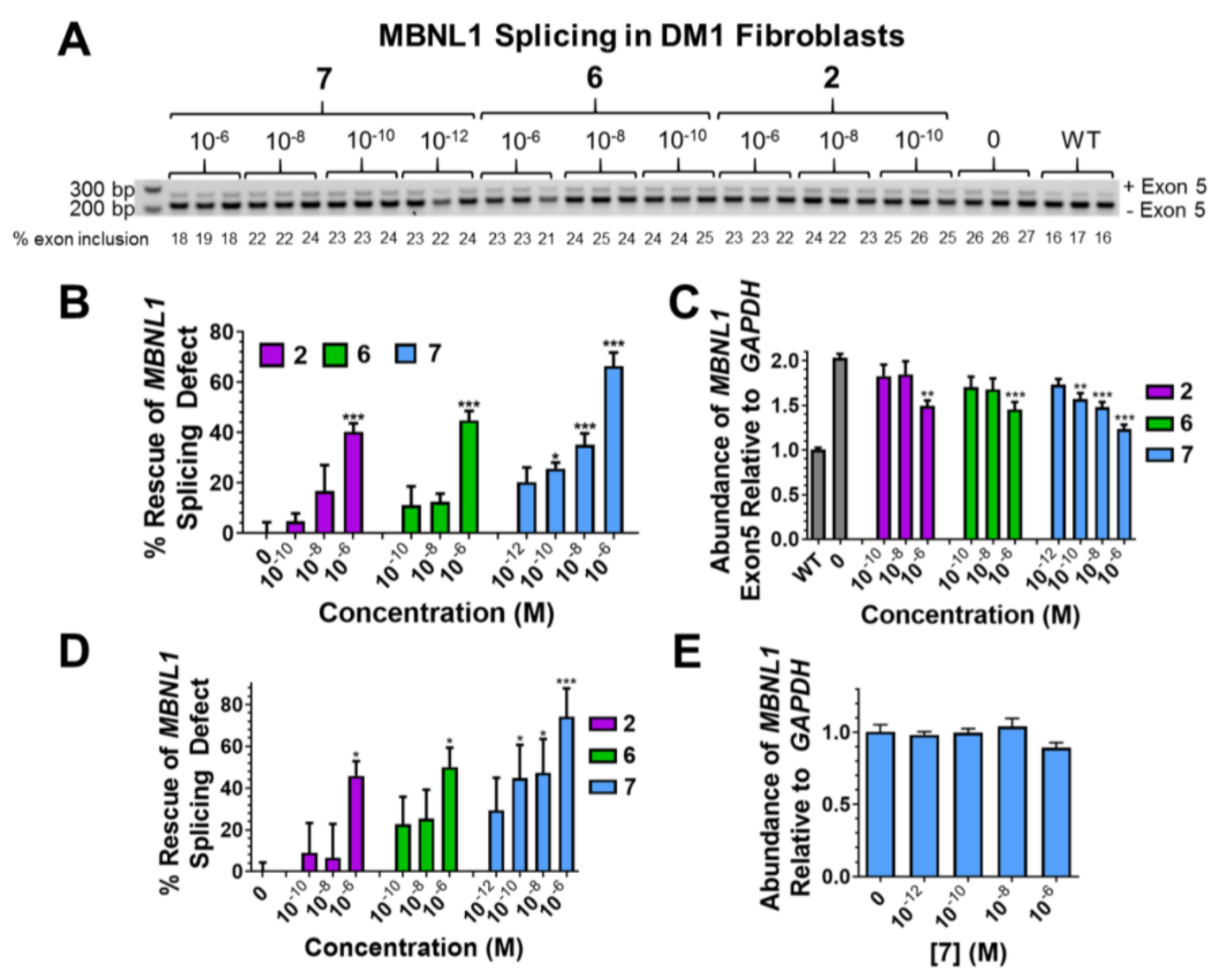

Figure S10. Activity of compounds in DM1 patient-derived fibroblasts. (A) Representative gel image to quantify MBNL1 exon 5 alternative splicing in DM1 fibroblasts. (B) Quantification of rescue of MBNL1 exon 5 splicing by RT-PCR and gel analysis, as calculated by Equation $1(n=$ 6). (C) RT-qPCR quantification of MBNL1 exon 5 abundance $(n=6)$. (D) Quantification of rescue of MBNL1 exon 5 splicing rescue from RT-qPCR data in C $(n=6)$. (E) RT-qPCR quantification of total MBNL1 mRNA levels $(\mathrm{n}=3)$. For all panels, error bars represent SD; ${ }^{*} P<0.05,{ }^{* \star} P<$ $0.01,{ }^{* * *} P<0.001$, as determined by one-way ANOVA relative to untreated samples. 


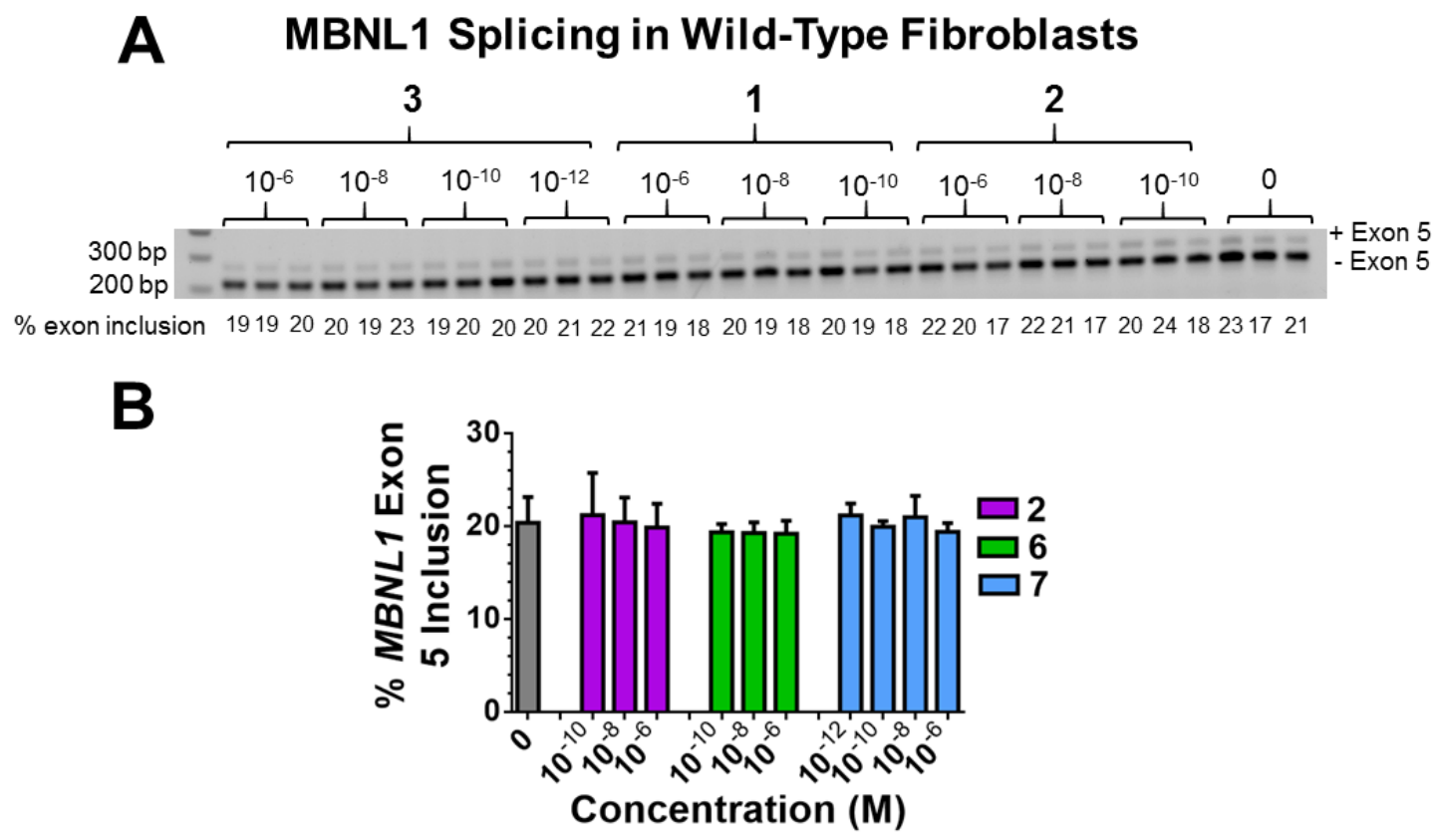

Figure S11. Activity of compounds in wild-type fibroblasts. (A) Representatives gel image of MBNL1 exon 5 alternative splicing in wild-type fibroblasts. (B) Quantification of MBNL1 exon 5 inclusion $(n=3)$. Error bars represent SD. 

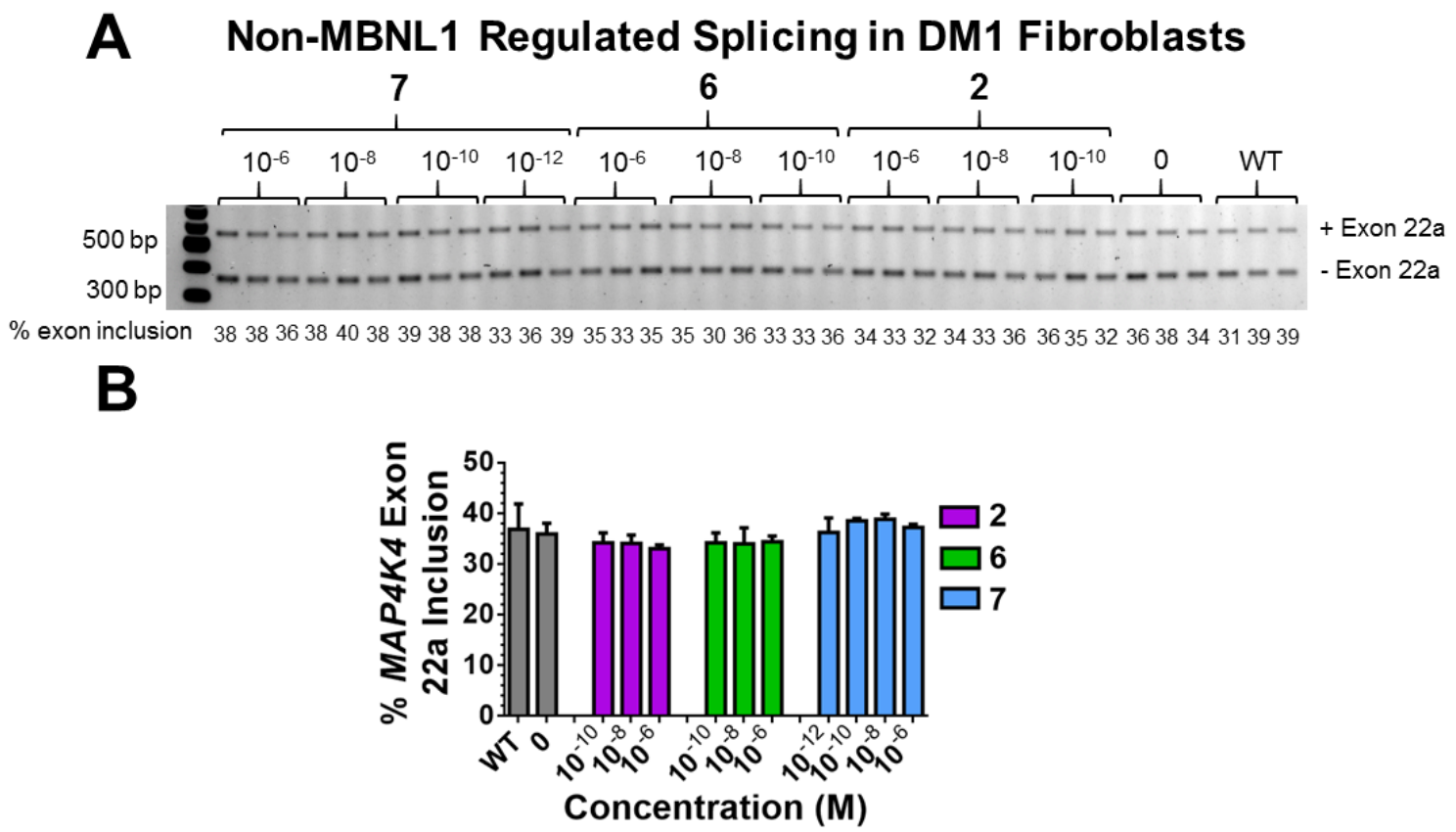

Figure S12. Non-MBNL1 regulated splicing event in DM1 fibroblasts upon treatment with various compounds. (A) Representative gel image of MAP4K4 exon 22a alternative splicing (NOVAregulated splicing). (B) Quantification of MAP4K4 exon 22a inclusion $(\mathrm{n}=3)$. Error bars represent SD. 


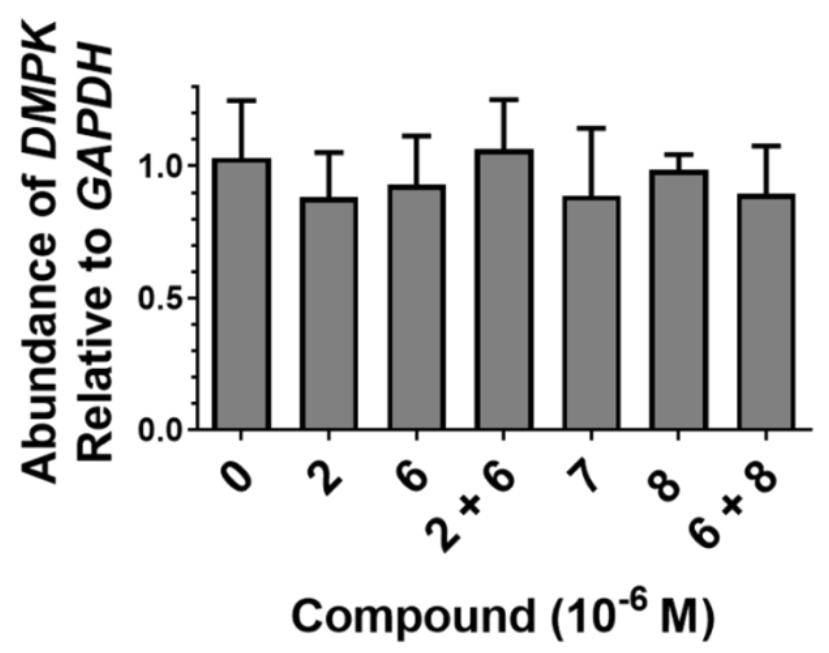

Figure S13. Abundance of DMPK mRNA in DM1 patient-derived fibroblasts, as determined by RT-qPCR $(n=6)$. Error bars represent SD. 


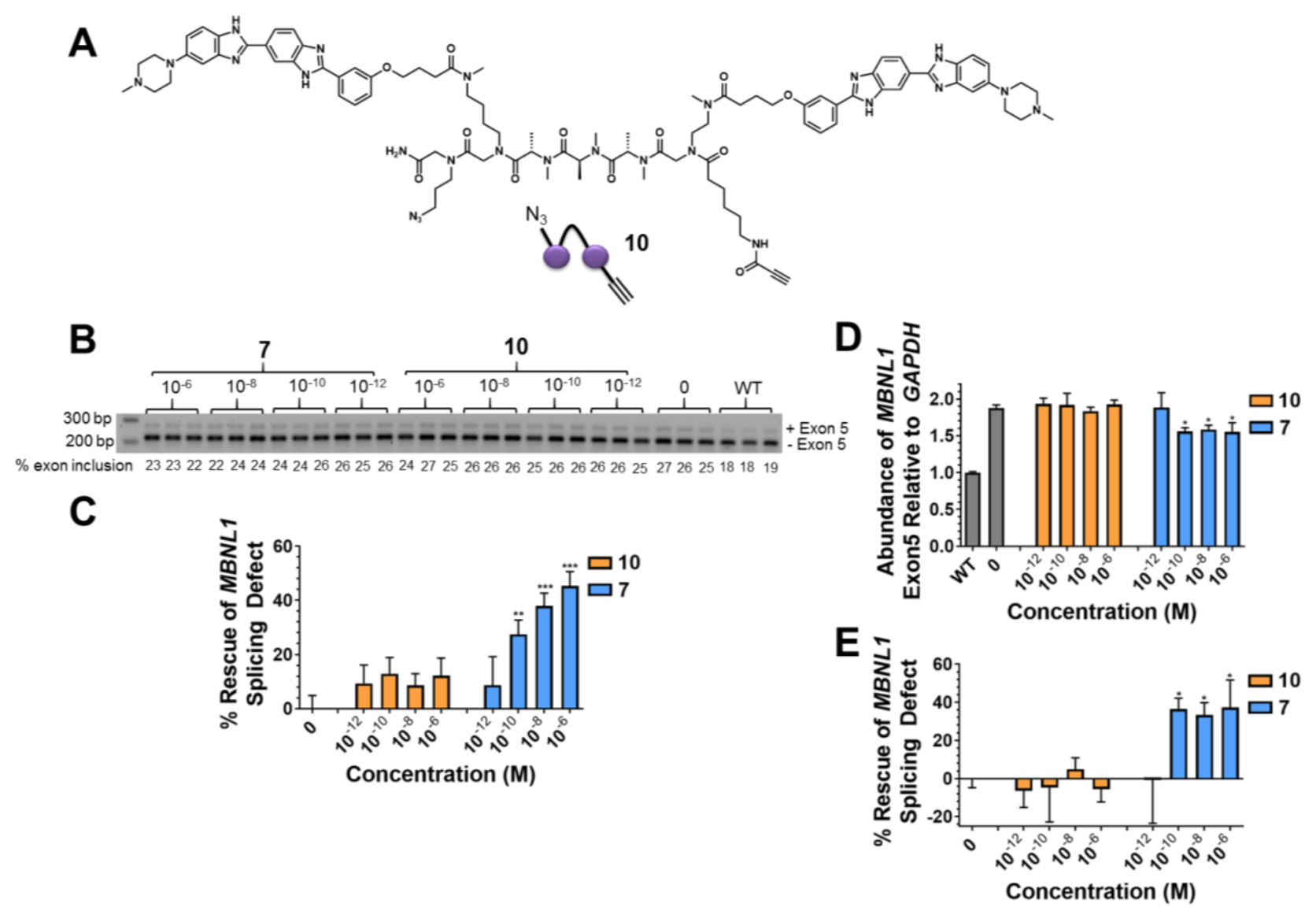

Figure S14. Comparison of $r(C U G)$ exp-templated azide-alkyne and tetrazine-cyclopropene chemistry after $24 \mathrm{~h}$. (A) Structure of compound 10. (B) Representative gel image of MBNL1 exon 5 alternative splicing in DM1 patient-derived fibroblasts. (C) Quantification of rescue of MBNL1 exon 5 splicing by RT-PCR and gel analysis, as calculated by Equation 1. (D) RT-qPCR quantification of MBNL1 exon 5 abundance. (E) Quantification of rescue of MBNL1 exon 5 splicing rescue from RT-qPCR data in C. For all panels, $\mathrm{n}=6$, and error bars represent SD; * $P$ $<0.05,{ }^{* *} P<0.01,{ }^{* *} P<0.001$, as determined by one-way ANOVA relative to untreated samples. 


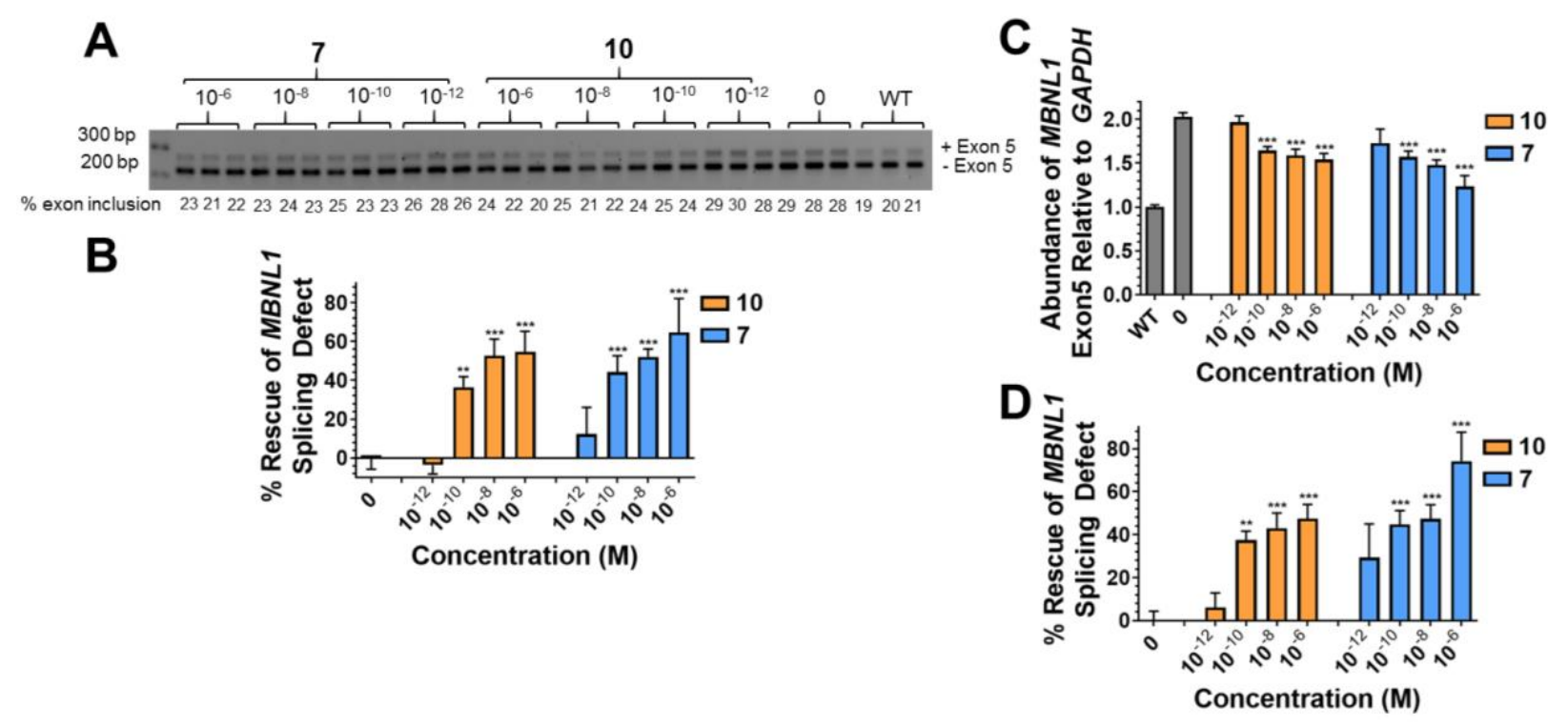

Figure S15. Comparison of $r(C U G)_{\text {exp-templated azide-alkyne and tetrazine-cyclopropene }}$ chemistry after $48 \mathrm{~h}$. (A) Representative gel image of MBNL1 exon 5 alternative splicing in DM1 fibroblasts. (B) Quantification of rescue of MBNL1 exon 5 splicing by RT-PCR and gel analysis, as calculated by Equation 1. (C) RT-qPCR quantification of MBNL1 exon 5 inclusion. (D) Quantification of rescue of MBNL1 exon 5 splicing rescue from RT-qPCR data in C. For all panels, $\mathrm{n}=6$ and error bars represent SD; ${ }^{*} P<0.01,{ }^{* * *} P<0.001$, as determined by one-way ANOVA relative to untreated samples. 


\section{Experimental Methods:}

General procedure for RNA-templated click reaction in vitro: The RNA of interest (purchased from Dharmacon and deprotected according to the recommended protocol), r(CUG) 12, $r(C U G)_{24}$, or $\mathrm{r}(\mathrm{GC}) 8,\left(25 \mu \mathrm{M}\right.$ final concentration) was folded in $1 \times$ Assay Buffer $\left(8 \mathrm{mM} \mathrm{Na} 2 \mathrm{HPO}_{4}, \mathrm{pH} 7.0,185\right.$ $\mathrm{mM} \mathrm{NaCl}$ and $1 \mathrm{mM} \mathrm{EDTA}$ ) at $60{ }^{\circ} \mathrm{C}$ for $5 \mathrm{~min}$. After cooling, reactive compound pairs (final concentration of $10 \mu \mathrm{M}$ each) or $7(20 \mu \mathrm{M}$ final concentration) were added to the RNA in a total volume of $30 \mu \mathrm{L}$, and the samples were incubated at $37^{\circ} \mathrm{C}$ for the indicated times. For each timepoint, $5 \mu \mathrm{L}$ aliquots of the reaction mixture were removed, and RNA was degraded with RNase $\mathrm{A}(0.2 \mathrm{ng})$ for $5 \mathrm{~min}$ at room temperature. Samples were then acidified to $\mathrm{pH} 5$ with water + TFA, and the samples were purified by C18 ZipTip (Millipore) per the manufacturer's recommended protocol. Eluted samples were analyzed using an Applied Biosystems MALDI ToF/ToF Analyzer 4800 Plus using an a-cyano-4-hydroxycinnamic acid matrix. Percent reaction was calculated by extrapolation of a standard curve, generated by taking the ratio of the total ion count of tetramer product to the total ion count of starting material 6 when the two compounds were mixed at different concentrations (total concentration $=10 \mu \mathrm{M}$ in all cases).

RNA-templated fluorogenic click reaction in vitro: The $R N A, r(C U G){ }_{12}$ or $r(G C) 8(2.5 \mu M$ final concentration), was folded as described above. After cooling, 6 and 8 ( $1 \mu \mathrm{M}$ each) were added. The samples were incubated at $37^{\circ} \mathrm{C}$ and fluorescence was measured at various timepoints using a using a BioTek FLX-800 fluorescence plate reader with excitation/emission of 480/530 nm. Enhancement of fluorescence was calculated relative to the reaction without RNA. For measuring fluorescence spectra, reactions were incubated as described above, and then fluorescence spectra were collected on a Molecular Devices Spectramax M5 with 485 nm excitation with 495 nm cutoff. For measuring absorbance spectra, reactions were incubated as described above and 
then transferred to a cuvette where an absorbance wavelength scan was performed on a Beckman Coulter DU800 spectrophotometer from 200 to $800 \mathrm{~nm}$.

Live-cell imaging of fluorogenic click reaction in patient-derived fibroblasts: The reaction of 6 and 8 was monitored in cells via live-cell fluorescence microscopy. DM1 patient-derived fibroblasts containing 500 r(CUG) repeats (GM03987, Coriell Institute) and wild-type fibroblasts from a healthy donor containing 20 r(CUG) repeats (GM07492, Coriell Institute) were grown in 96-well poly-D-lysine coated glass bottom plate (MatTek) in 1× MEM (Corning), 10\% fetal bovine serum (FBS), 1× Glutagro (Corning), 1× MEM non-essential amino acids (Corning), and 1x antibiotic/antimycotic solution (Corning) to $\sim 80 \%$ confluence. Cells were treated with $500 \mathrm{nM}$ each of $\mathbf{6}$ and 8 or $500 \mathrm{nM}$ of 8 alone. At appropriate timepoints, cells were washed with $1 \times$ DPBS and imaged in 1× DPBS using an Olympus FluoView 1000 confocal microscope. For experiments using Lysotracker, cells were washed with 1× DPBS and stained with 100 nM LysoTracker RedDND 99 (ThermoFisher) for $1 \mathrm{~h}$. Cells were then washed with $1 \times$ DPBS and imaged in $1 \times$ DPBS. For experiments using 9 or TCO, r(CUG) 500 fibroblasts were treated with $500 \mathrm{nM} 8$ for $12 \mathrm{~h}$ and then washed with $1 \times$ DPBS. They were then treated with $2 \mu \mathrm{M}$ TCO or 9 for $4 \mathrm{~h}$. After the incubation period, the cells were washed with $1 \times$ DPBS, stained with Lysotracker as described above, and imaged in $1 \times$ DPBS. For experiments using $\mathrm{NH}_{4} \mathrm{Cl}$, cells were treated for $5 \mathrm{~h}$ with compound, followed by the addition of $20 \mathrm{mM} \mathrm{NH}_{4} \mathrm{Cl}$ to the cell culture medium. Cells were washed with $1 \times$ DPBS and imaged in $1 \times$ DPBS containing $20 \mathrm{mM} \mathrm{NH}_{4} \mathrm{Cl}$. Fluorescence intensity was calculated for each image using ImageJ.

Live imaging of fluorogenic click reaction in DM1 myofibers: Muscle fibers were isolated and cultured as previously described.1 Briefly, the extensor digitoris longus (EDL) muscles of HSALR (DM1 mice) and FVB (Jackson Labs) mice were dissected and digested in $2 \mathrm{~mL}$ of a $0.2 \%$ 
collagenase type 1 solution in $1 \times$ DMEM with L-glutamine and sodium pyruvate (Corning) at 37 ${ }^{\circ} \mathrm{C}$ for 45 min. Individual myofibers were then separated by flushing the muscle with $1 \times$ DMEM with L-glutamine and sodium pyruvate and $1 \times$ antibiotic/antimycotic solution. Isolated myofibers were cultured in $1 \times$ DMEM with L-glutamine and sodium pyruvate, $20 \% \mathrm{FBS}$, and $1 \times$ antibiotic/antimycotic solution. Myofibers were treated with $500 \mathrm{nM}$ each of 6 and 8 or $500 \mathrm{nM} 8$ alone for $48 \mathrm{~h}$ in growth medium at $37^{\circ} \mathrm{C}$. Myofibers were carefully transferred to a 96 -well polyD-lysine coated glass bottom plate using a Pasteur pipette coated with horse serum (Life Technologies). Myofibers were then stained with $5 \mu \mathrm{M}$ Hoechst 33258 in growth medium for 30 min at $37^{\circ} \mathrm{C}$. Myofibers were imaged in $1 \times$ Fluorbrite DMEM with L-glutamine and sodium pyruvate, 20\% FBS, and 1x antibiotic/antimycotic solution using an Olympus FluoView 1000 confocal microscope. Fluorescence intensity was calculated for each image using ImageJ.

Live-cell imaging of compound permeability: DM1 patient-derived fibroblasts were grown in a 96-well poly-D-lysine coated glass bottom plate (MatTek) as described above. Cells were treated with $1 \mu \mathrm{M}$ each of 6 or Tetramer. After $24 \mathrm{~h}$, cells were washed with $1 \times$ DPBS and imaged in $1 \times$ DPBS using an Olympus FluoView 1000 confocal microscope at 100× magnification.

Evaluation of nuclear foci using RNA fluorescence in situ hybridization (RNA-FISH): Nuclear foci were imaged by RNA-FISH as previously described.2 Cells were grown in a 96-well poly-D-lysine coated glass bottom plates and treated with $1 \mu \mathrm{M} \mathrm{2,} \mathrm{6,} \mathrm{or} 7$. After $48 \mathrm{~h}$, cells were fixed followed by FISH as previously described using $1 \mathrm{ng} / \mu \mathrm{L}$ DY547-2'OMe-(CAG)6.2 Immunostaining of MBNL1 was completed as previously described using the MB1a antibody (diluted 1:4), which was generously supplied by Prof. Glenn E. Morris (Wolfson Centre for Inherited Neuromuscular Disease), 3 and goat anti-mouse IgG-DyLight 488 conjugate (1:2000 dilution; ThermoFisher). Nuclei were stained using a $1 \mu \mathrm{g} / \mu \mathrm{L}$ solution of DAPI in $1 \times$ DPBS at 37 ${ }^{\circ} \mathrm{C}$ for $10 \mathrm{~min}$. Cells were imaged in 1× DPBS using an Olympus FluoView 1000 confocal 
microscope at $100 \times$ magnification. The number of $r(C U G)$ exp-MBNL1 foci were counted in 40 cells/replicate (120 total cells counted over three biological replicates).

Evaluation of pre-mRNA splicing using RT-PCR: DM1 and wild-type fibroblasts were grown in 6-well plates in growth medium and treated with the indicated concentrations of compound. After $48 \mathrm{~h}$, the cells were lysed, and total RNA was harvested using a Zymo Quick-RNA Miniprep Kit per the manufacturer's recommended protocol. Approximately $250 \mathrm{ng}$ of total RNA was reverse transcribed at $50{ }^{\circ} \mathrm{C}$ using 100 units of SuperScript III reverse transcriptase (Life Technologies). Next, $20 \%$ of the RT reaction was subjected to PCR using GoTaq DNA polymerase (Promega) and primers for MBNL1 or MAP4K4 splicing (MBNL1 Fwd: 5'GCTGCCCAATACCAGGTCAAC-3'; MBNL1 Rev: 5'-TGGTGGGAGAAATGCTGTATGC-3'; MAP4K4 Fwd: 5'-CCTCATCCAGTGAGGAGTCG-3'; MAP4K4 Rev: 5'ATCACAGGAAAATCCCACCA). RT-PCR products were observed after 30 cycles of $95{ }^{\circ} \mathrm{C}$ for $30 \mathrm{~s}, 58{ }^{\circ} \mathrm{C}$ for $30 \mathrm{~s}, 72{ }^{\circ} \mathrm{C}$ for $1 \mathrm{~min}$ and a final extension at $72{ }^{\circ} \mathrm{C}$ for $5 \mathrm{~min}$. Products were separated on a $2 \%$ agarose gel run at $100 \mathrm{~V}$ for $1 \mathrm{~h}$ in $1 \times$ TBE buffer, visualized by staining with ethidium bromide, and imaged using a Typhoon 9410 variable mode imager. Gels were quantified using ImageJ. Percent rescue was calculated using equation 1:

$$
\% \text { Rescue }=\frac{\% \text { exon inclusion DM1-\% exon inclusion treated }}{\% \text { exon inclusion } D M 1-\% \text { exon inclusion } W T}
$$

Evaluation of MBNL1 exon 5, MBNL1, and DMPK transcript levels by RT-qPCR: DM1 and wild-type fibroblasts were grown in 6-well plates in growth medium, treated with compound, and total RNA harvested and reverse transcribed as described in Evaluation of pre-mRNA splicing using RT-PCR. Next, $2 \mu \mathrm{L}$ of the RT reaction was used for each primer pair for qPCR with SYBR Green Master Mix performed on a 7900HT Fast Real-Time PCR System. Relative abundance of each transcript was determined by normalizing to GAPDH. Primer sets: MBNL1 exon 5 Fwd: 5'CTCAGTCGGCTGTCAAATCA-3', MBNL1 exon 5 Rev: 5'-AGAGCAGGCCTCTTTGGTAA-3'; 
MBNL1 Fwd: 5'-TTCATCCACCCCCACATTTA-3', MBNL1 Rev: 5'TTGGCTAGTTGCATTTGCTG-3'; DMPK Fwd: 5'-CGTGCAAGCGCCCAG-3', DMPK Rev: 5'CTCCACCAACTTACTGTTTCATCCT-3'; GAPDH Fwd: 5'-AAGGTGAAGGTCGGAGTCAA-3'; GAPDH Rev: 5'-AATGAAGGGGTCATTGATGG-3'.

Evaluation of nucleocytoplasmic transport using a luciferase reporter assay: $\mathrm{C} 2 \mathrm{C} 12$ cells that stably express 800 or 0 r(CUG) repeats in the 3' UTR of firefly luciferase 4 were grown in 96well plates in growth medium (1× DMEM, 10\% FBS, $1 \times$ Glutagro, and $1 \times$ antibiotic/antimycotic solution). When the cells reached $\sim 70 \%$ confluency, compounds were added, and cells were treated for $48 \mathrm{~h}$. Cell count was normalized using WST-1 reagent (Roche) according to the manufacturer's protocol. After removal of WST-1 reagent and washing with $1 \times$ DPBS, luminescence was measured using ONE-Glo luciferase assay system (Promega) according to the manufacturer's protocol. Luminescence was measured using a Bio-Tek FLX-800 plate reader.

\section{Synthetic Methods:}

General Synthetic Methods: N-methyl peptides were synthesized using a Biotage Initiator+ SP Wave microwave as previously described 2 and as described below. Microwave irradiation was completed in a $700 \mathrm{~W}$ microwave set to $10 \%$ power $(3 \times 15$ s) unless otherwise noted. Peptide synthesis reactions were monitored by chloranil test. Preparative HPLC was performed using a Waters 1525 Binary HPLC pump equipped with a Waters 2489 dual absorbance detector system and a Waters Sunfire C18 OBD $5 \mu \mathrm{m} 19 \times 150 \mathrm{~mm}$ column using a gradient of $0-100 \%$ methanol $(\mathrm{MeOH})$ in water with $0.1 \%$ trifluoracetic acid (TFA) over 60 min. Purity was assessed by analytical HPLC using a Waters Symmetry C18 $5 \mu \mathrm{m} 4.6$ x $150 \mathrm{~mm}$ column. Small molecules were analyzed using a gradient of $0-100 \%$ methanol $(\mathrm{MeOH})$ in water with $0.1 \%$ trifluoracetic acid (TFA) over $60 \mathrm{~min}$, and absorbance was measured at 220 and $254 \mathrm{~nm}$. Mass spectrometry was 
performed with an Applied Biosystems MALDI ToF Analyzer 4800 Plus using an a-cyano-4hydroxycinnamic acid matrix. NMR spectra were collected on a $400 \mathrm{MHz}$ Bruker.

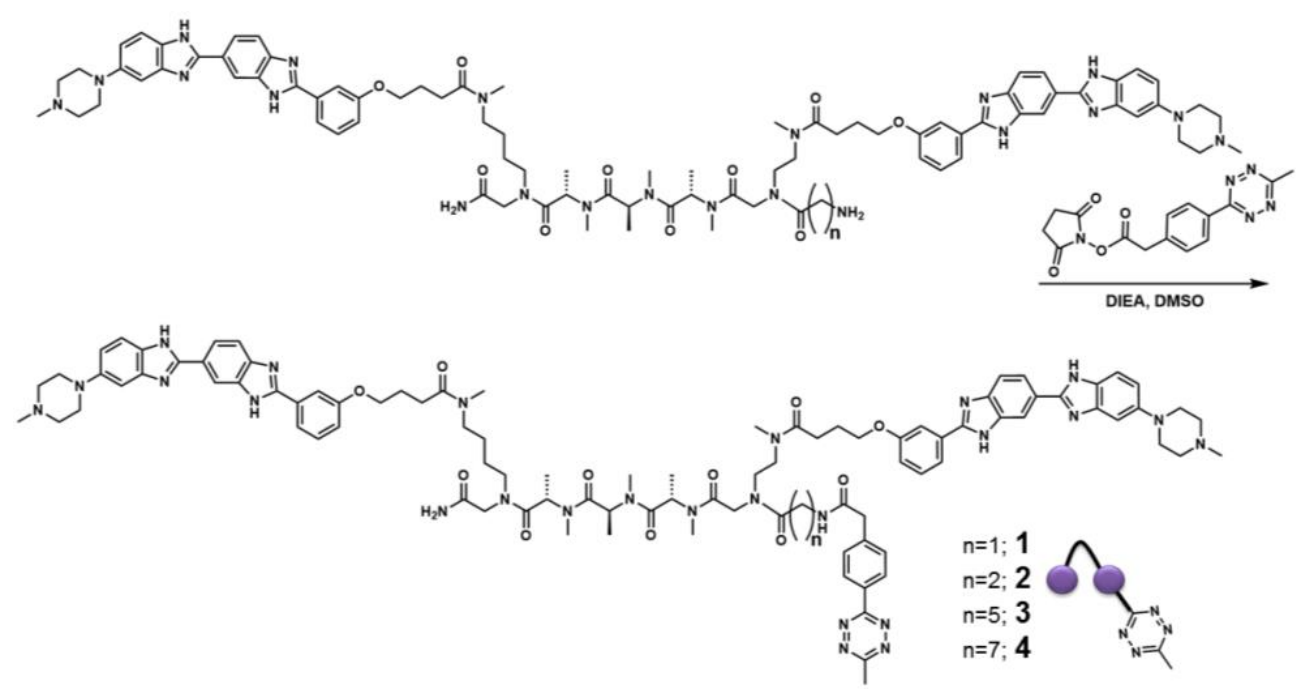

General Procedure for Synthesis of 1 - 4: $2 \mathrm{H}-\mathrm{K} 4 \mathrm{NMeS}$ derivatives with different linkers were synthesized as previously described.2 Methyltetrazine NHS ester (2 equiv; Click Chemistry Tools) was added to $2 \mathrm{H}-\mathrm{K} 4 \mathrm{NMeS}$ functionalized with an amine linker of interest in dimethyl sulfoxide (DMSO) with $\mathrm{N}, \mathrm{N}$-diisopropylethylamine (DIEA; 4 equiv). The reaction was stirred at room temperature for $3 \mathrm{~h}$, and then the mixture was purified by HPLC as described in General Synthetic Methods.

For 1: $1 \mu \mathrm{mol}$ of glycine-functionalized $2 \mathrm{H}-\mathrm{K} 4 \mathrm{NMeS}$ was used for the synthesis described above to yield 330 nmoles of $\mathbf{1} ; 33 \%$ yield. $\mathbf{1}\left(\mathrm{C}_{95} \mathrm{H}_{115} \mathrm{~N}_{25} \mathrm{O}_{11}\right)$ calculated masses: $1782.9281(\mathrm{M}+\mathrm{H})$; mass found: $1782.9165(M+H) ; t_{R}=34 \mathrm{~min}$.

For 2: $5 \mu \mathrm{mol}$ of $\beta$-Alanine-functionalized $2 \mathrm{H}-\mathrm{K} 4 \mathrm{NMeS}$ was used for the synthesis described above to yield 2.8 umoles of $2 ; 56 \%$ yield. $2\left(\mathrm{C}_{96} \mathrm{H}_{117} \mathrm{~N}_{25} \mathrm{O}_{11}\right)$ calculated mass: $1796.9437(\mathrm{M}+$ $H)$; mass found: $1796.9290(M+H) ; t R=34 \min$. 
For 3: $1 \mu \mathrm{mol}$ of 6-aminohexanoic acid-functionalized 2H-K4NMeS was used for the synthesis described above to yield 400 nmoles of $3 ; 40 \%$ yield. $3\left(\mathrm{C}_{99} \mathrm{H}_{123} \mathrm{~N}_{25} \mathrm{O}_{11}\right)$ calculated mass: 1838.9907 $(\mathrm{M}+\mathrm{H})$; mass found: $1838.9784(\mathrm{M}+\mathrm{H}) ; \mathrm{tR}=37 \mathrm{~min}$.

For 4: $2 \mu \mathrm{mol}$ of 8-aminooctanoic acid-functionalized 2H-K4NMeS was used for the synthesis described above to yield 800 nmoles of $4 ; 40 \%$ yield. $4\left(\mathrm{C}_{101} \mathrm{H}_{127} \mathrm{~N}_{25} \mathrm{O}_{11}\right)$ calculated mass: $1867.0220(\mathrm{M}+\mathrm{H})$; mass found: $1869.0029(\mathrm{M}+\mathrm{H}) ; \mathrm{tR}=39 \mathrm{~min}$.

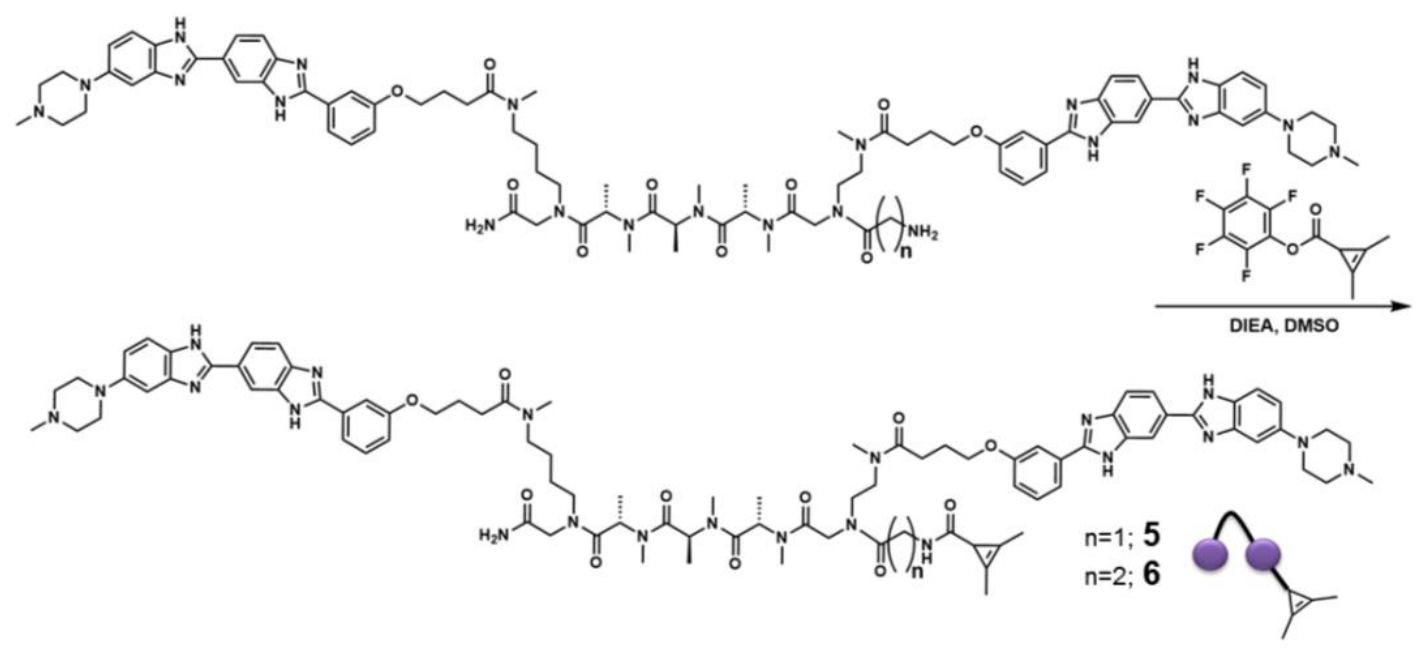

General Procedure for Synthesis of 5 and 6: $2 \mathrm{H}-\mathrm{K} 4 \mathrm{NMeS}$ derivatives with different linkers were synthesized as previously described.2 Activated cyclopropene (2 equiv) was synthesized as previously described 5 and was added to $2 \mathrm{H}-\mathrm{K} 4 \mathrm{NMeS}$ with an amine linker in DMSO with DIEA (4 equiv). The reaction was stirred at room temperature for $3 \mathrm{~h}$, and then the mixture was purified by HPLC as indicated in General Synthetic Methods.

For 5: $1.5 \mu \mathrm{mol}$ of glycine-functionalized $2 \mathrm{H}-\mathrm{K} 4 \mathrm{NMeS}$ was used for the synthesis described above to yield 620 nmoles of $5 ; 41 \%$ yield. $5\left(\mathrm{C}_{90} \mathrm{H}_{113} \mathrm{~N}_{21} \mathrm{O}_{11}\right)$ calculated mass: $1664.9001(\mathrm{M}+\mathrm{H})$; mass found: $1664.8929(M+H) ; t_{R}=33 \mathrm{~min}$. 
For 6: $5.5 \mu \mathrm{mol}$ of $\beta$-Alanine-functionalized $2 \mathrm{H}-\mathrm{K} 4 \mathrm{NMeS}$ was used for the synthesis described above to yield $3.3 \mu$ moles of $6 ; 60 \%$ yield. $6\left(\mathrm{C}_{91} \mathrm{H}_{115} \mathrm{~N}_{21} \mathrm{O}_{11}\right)$ calculated masses: $1678.9158(\mathrm{M}+$ $H)$; mass found $1678.9113(\mathrm{M}+\mathrm{H})$; $\mathrm{tR}=34 \mathrm{~min}$.

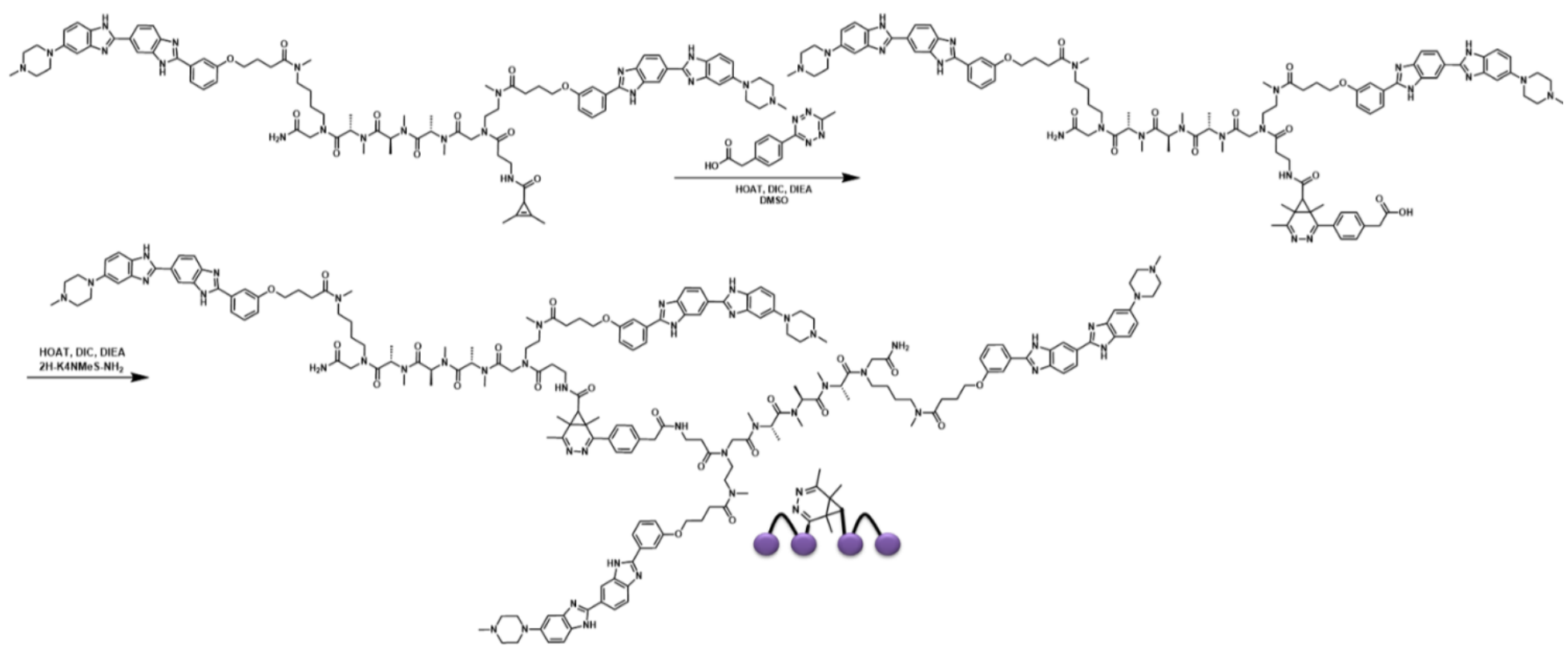

Synthesis of Tetramer Standard: Compound 6 was synthesized as described above. To synthesize a tetramer standard, 200 nmoles of 6 was reacted with 600 nmoles (3 equiv) of tetrazine carboxylic acid (Click Chemistry Tools) in DMSO by heating at $60{ }^{\circ} \mathrm{C}$ for $2 \mathrm{~h}$. The reaction was then HPLC purified as described in General Synthetic Methods. The carboxylic acid (75 nmoles) was then coupled to $2 \mathrm{H}-\mathrm{K} 4 \mathrm{NMeS}-\beta$-Alanine-NH 22 (150 nmoles, 2 equiv) with 1 hydroxy-7-azabenzotriazole (HOAT; 225 nmoles, 3 equiv), N,N-diisopropylcarbodiimide (DIC; 450 nmoles, 6 equiv), and DIEA (450 nmoles, 6 equiv) in DMSO at room temperature overnight. The reaction was then HPLC purified as described above, affording 5 nmoles of tetramer $(2.5 \%$ yield). Tetramer $\left(\mathrm{C}_{187} \mathrm{H}_{232} \mathrm{~N}_{44} \mathrm{O}_{22}\right)$ calculated masses: $3446.8461(\mathrm{M}+\mathrm{H})$ and $3468.8286(\mathrm{M}+$ $\mathrm{Na})$; masses found $3447.0537(\mathrm{M}+\mathrm{H})$ and $3469.0618(\mathrm{M}+\mathrm{Na})$; $\mathrm{tR}_{\mathrm{r}}=34 \mathrm{~min}$. 


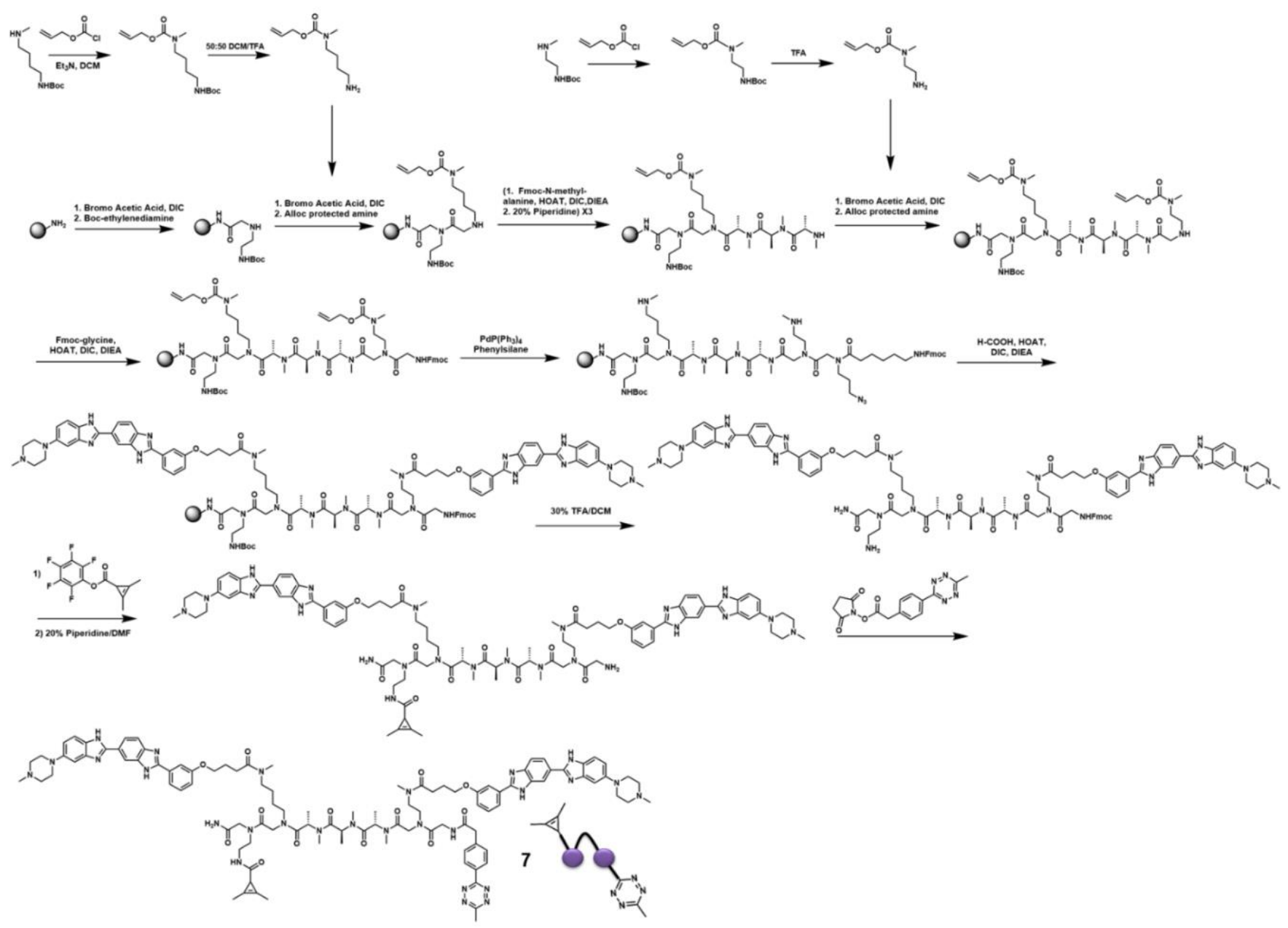

Synthesis of 7: Allyloxycarbonyl (Alloc)-protected amines were synthesized as previously described.6 Briefly, tert-butyl (4-(methylamino)butyl)carbamate or tert-butyl (2(methylamino)ethyl)carbamate $(1 \mathrm{~g})$ were dissolved in dichloromethane (DCM, $50 \mathrm{~mL})$ followed by the addition of allyl chloroformate ( 2 equiv) and triethylamine ( 5 equiv) at $0{ }^{\circ} \mathrm{C}$. The reactions were warmed to room temperature for $1 \mathrm{~h}$ then washed with $5 \% \mathrm{HCl}$, then washed with saturated sodium bicarbonate. The organic phase was dried over sodium sulfate and concentrated in vacuo. The alloc-protected amines were then deprotected with $30 \%$ TFA/DCM for 30 min, concentrated, and used for solid phase synthesis without further purification. Rink amide resin (1 $\mathrm{g}, 0.6 \mathrm{mmol}$ ) was swollen in dimethylformamide (DMF) at room temperature for $10 \mathrm{~min}$ and then deprotected with a solution of $20 \%$ piperidine in DMF ( $5 \mathrm{~mL}, 2 \times 20 \mathrm{~min})$. The resin was washed 
with DMF $(3 \times 5 \mathrm{~mL})$ and reacted twice with a solution of $1 \mathrm{M}$ bromoacetic acid $(4 \mathrm{~mL})$ in DMF and DIC (250 $\mu \mathrm{L}, 1.6 \mathrm{mmol})$ via microwave irradiation as specified in General Synthetic Methods. The resin was washed with DMF $(3 \times 5 \mathrm{~mL})$ and reacted with a solution of bocethylenediamine $(300 \mathrm{mg})$ with DIEA $(250 \mu \mathrm{L})$ in DMF $(4 \mathrm{~mL})$ via microwave irradiation. The resin was shaken with this solution at room temperature for an additional $1 \mathrm{~h}$ and then washed with DMF $(3 \times 5 \mathrm{~mL})$. The resin was washed with DMF $(3 \times 5 \mathrm{~mL})$ and reacted twice with a solution of $1 \mathrm{M}$ bromoacetic acid $(4 \mathrm{~mL})$ in DMF and DIC $(250 \mu \mathrm{L}, 1.6 \mathrm{mmol})$ via microwave irradiation. The resin was washed with DMF $(3 \times 5 \mathrm{~mL})$ and reacted with a solution of allyl-(4aminobutyl)methyl)carbamate (300 mg) with DIEA $(250 \mu \mathrm{L})$ in DMF $(4 \mathrm{~mL})$ via microwave irradiation. The resin was shaken with this solution at room temperature for an additional $1 \mathrm{~h}$ and then washed with DMF ( $3 \times 5 \mathrm{~mL})$. Then, a solution of Fmoc-N-methyl-L-alanine (500 mg), DIC $(250 \mu \mathrm{L})$, HOAt $(200 \mathrm{mg})$, and DIEA $(200 \mu \mathrm{L})$ in DMF $(8 \mathrm{~mL})$ was added and the reaction was heated via microwave reactor to $75^{\circ} \mathrm{C}$ for $10 \mathrm{~min}$. The resin was washed with DMF, and the Fmoc was removed with $20 \%$ piperidine/DMF $(2 \times 10 \mathrm{~min})$. This cycle was repeated two additional times. The resin was washed with DMF $(3 \times 5 \mathrm{~mL})$ and reacted twice with a solution of $1 \mathrm{M}$ bromoacetic acid $(4 \mathrm{~mL})$ in DMF and DIC ( $250 \mu \mathrm{L}, 1.6 \mathrm{mmol})$ via microwave irradiation. The resin was washed with DMF $(3 \times 5 \mathrm{~mL})$ and reacted with a solution of allyl-(2aminoethyl)(methyl)carbamate $(300 \mathrm{mg})$ with DIEA $(250 \mu \mathrm{L})$ in DMF $(4 \mathrm{~mL})$ via microwave irradiation. The resin was shaken with this solution at room temperature for an additional $1 \mathrm{~h}$ and then washed with DMF $(3 \times 5 \mathrm{~mL})$. Then, a solution of Fmoc-glycine $(500 \mathrm{mg})$, DIC $(250 \mu \mathrm{L})$, HOAt $(200 \mathrm{mg})$, and DIEA $(200 \mu \mathrm{L})$ in DMF $(8 \mathrm{~mL})$ was added and the reaction was heated via microwave reactor to $75{ }^{\circ} \mathrm{C}$ for $10 \mathrm{~min}$. The resin was then washed with DMF $(3 \times 5 \mathrm{~mL})$ and DCM $(3 \times 5 \mathrm{~mL})$. The Alloc protecting group was removed with $\mathrm{Pd}\left(\mathrm{PPh}_{3}\right)_{4}(100 \mathrm{mg})$ and phenylsilane $(100 \mu \mathrm{L})$ in DCM $(2 \times 10 \mathrm{~min})$. The resin was washed with DCM and dry DMF, and then a solution of $\mathrm{H}$ carboxylic acid (500 mg; synthesized as previously described7), DIC ( $250 \mu \mathrm{L})$, HOAt $(200 \mathrm{mg})$, and DIEA $(200 \mu \mathrm{L})$ in DMF $(8 \mathrm{~mL})$ was added. The reaction was heated via 
microwave reactor to $75^{\circ} \mathrm{C}$ for $1 \mathrm{~h}$. After washing the resin with DMF and DCM, the product was cleaved from the resin with $30 \% \mathrm{TFA} / \mathrm{DCM}$ for $10 \mathrm{~min}$ at room temperature. The solution was concentrated in vacuo and purified by HPLC with a $20-100 \%$ gradient of $\mathrm{MeOH}$ in water $+0.1 \%$ TFA. Cyclopropene was then added to the dimer $(3 \mu \mathrm{mol})$ as described above, and the reaction was HPLC purified with a $20-100 \%$ gradient of $\mathrm{MeOH}$ in water $+0.1 \%$ TFA. Fmoc was deprotected in solution with $0.5 \mathrm{~mL}$ of $20 \%$ piperidine/DMF, and the reaction was HPLC purified with a $20-100 \%$ gradient of $\mathrm{MeOH}$ in water $+0.1 \%$ TFA. Tetrazine was then added to the dimer (500 nmol) as described above and the reaction was HPLC purified as described in General Synthetic Methods, affording 235 nmoles of $7 ; 0.04 \%$ yield overall. $7\left(\mathrm{C}_{105} \mathrm{H}_{129} \mathrm{~N}_{27} \mathrm{O}_{13}\right)$ calculated mass: $1977.0336(M+H)$; mass found: $1977.0327(M+H)$; tr $=34$ min. 

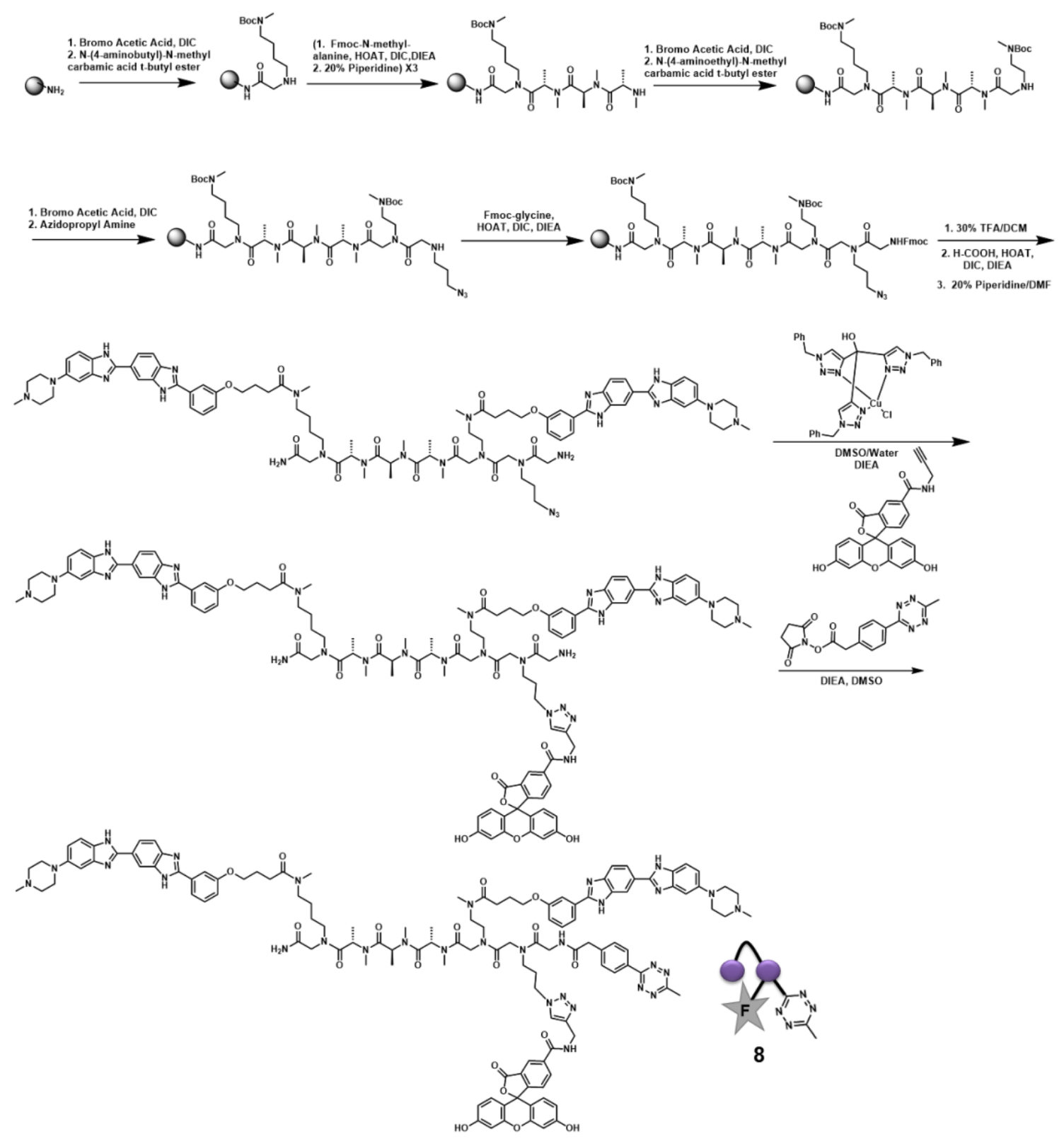

Synthesis of 8: Rink amide resin $(1 \mathrm{~g}, 0.6 \mathrm{mmol})$ was swollen in DMF at room temperature for $10 \mathrm{~min}$ and then deprotected with a solution of $20 \%$ piperidine in DMF ( $5 \mathrm{~mL}, 2 \times 20 \mathrm{~min})$. The resin was washed with DMF $(3 \times 5 \mathrm{~mL})$ and reacted twice with a solution of $1 \mathrm{M}$ bromoacetic acid $(4 \mathrm{~mL})$ in DMF and DIC $(250 \mu \mathrm{L}, 1.6 \mathrm{mmol})$ via microwave irradiation as specified in General Synthetic Methods. The resin was washed with DMF $(3 \times 5 \mathrm{~mL})$ and reacted with a solution of $\mathrm{N}$-(4-aminobutyl)- N-methyl carbamic acid tert-butyl ester (300 mg) with DIEA (250 $\mu \mathrm{L})$ in DMF $(4$ 
$\mathrm{mL}$ ) via microwave irradiation. The resin was shaken with this solution at room temperature for an additional $1 \mathrm{~h}$ and then washed with DMF $(3 \times 5 \mathrm{~mL})$. Then, a solution of Fmoc-N-methyl-Lalanine (500 mg), DIC $(250 \mu \mathrm{L})$, HOAt $(200 \mathrm{mg})$, and DIEA $(200 \mu \mathrm{L})$ in DMF $(8 \mathrm{~mL})$ was added, and the reaction was heated via microwave reactor to $75^{\circ} \mathrm{C}$ for $10 \mathrm{~min}$. The resin was washed with DMF, and the Fmoc was removed with $20 \%$ piperidine/DMF ( $2 \times 10 \mathrm{~min})$. This cycle was repeated two additional times. The resin was washed with DMF $(3 \times 5 \mathrm{~mL})$ and reacted twice with a solution of $1 \mathrm{M}$ bromoacetic acid $(4 \mathrm{~mL})$ in DMF and DIC $(250 \mu \mathrm{L}, 1.6 \mathrm{mmol})$ via microwave irradiation. The resin was washed with DMF $(3 \times 5 \mathrm{~mL})$ and reacted with a solution of $\mathrm{N}-(4-$ aminoethyl)-N-methyl carbamic acid tert-butyl ester $(300 \mathrm{mg})$ with DIEA $(250 \mu \mathrm{L})$ in DMF $(4 \mathrm{~mL})$ via microwave irradiation. The resin was shaken with this solution at room temperature for an additional $1 \mathrm{~h}$ and then washed with DMF $(3 \times 5 \mathrm{~mL})$. The resin was then reacted twice with a solution of $1 \mathrm{M}$ bromoacetic acid $(4 \mathrm{~mL})$ in DMF and DIC $(250 \mu \mathrm{L}, 1.6 \mathrm{mmol})$ via microwave irradiation. The resin was washed with DMF $(3 \times 5 \mathrm{~mL})$ and reacted with a solution of azidopropyl amine $(300 \mathrm{mg})$ with DIEA $(250 \mu \mathrm{L})$ in DMF $(4 \mathrm{~mL})$ via microwave irradiation. The resin was shaken with this solution at room temperature for an additional $1 \mathrm{~h}$ and then washed with DMF (3 $x 5 \mathrm{~mL})$. Then, a solution of Fmoc-glycine (500 mg), DIC (250 $\mu \mathrm{L})$, HOAt $(200 \mathrm{mg})$, and DIEA $(200 \mu \mathrm{L})$ in DMF $(8 \mathrm{~mL})$ was added and the reaction was heated via microwave reactor to $75^{\circ} \mathrm{C}$ for $10 \mathrm{~min}$. The resin was then washed with DMF $(3 \times 5 \mathrm{~mL})$ and DCM $(3 \times 5 \mathrm{~mL})$. The product was cleaved from the resin with $30 \%$ TFA/DCM for $10 \mathrm{~min}$ at room temperature. The solution was concentrated in vacuo and azeotroped with toluene three times. The resulting pale yellow oil was treated with a solution of $\mathrm{H}$ carboxylic acid $(80 \mathrm{mg}, 0.16 \mathrm{mmol}$; synthesized as previously described7), HOAt (22 mg, $0.16 \mathrm{mmol})$, DIC (100 $\mu \mathrm{L}, 0.64 \mathrm{mmol})$ and DIEA (100 $\mu \mathrm{L})$ in DMF (3 $\mathrm{mL}$ ) and heated via microwave reactor to $75^{\circ} \mathrm{C}$ for $1 \mathrm{~h}$. The reaction was HPLC purified with a $20-100 \%$ gradient of $\mathrm{MeOH}$ in water $+0.1 \%$ TFA. Fmoc was deprotected with $0.5 \mathrm{~mL}$ of $20 \%$ piperidine/DMF, and the reaction was HPLC purified with a $20-100 \%$ gradient of $\mathrm{MeOH}$ in water $+0.1 \%$ TFA. The resulting dimer $(6 \mu \mathrm{mol})$ was clicked with FAM alkyne 6 -isomer (Lumiprobe) $(2$ 
equiv) using copper (I) catalyst (0.1 equiv) in $1 \mathrm{~mL}$ of $1: 1 \mathrm{DMSO} /$ water with DIEA (3 equiv) by heating at $60{ }^{\circ} \mathrm{C}$ for $1 \mathrm{~h}$. The reaction was HPLC purified with a $20-100 \%$ gradient of $\mathrm{MeOH}$ in water $+0.1 \%$ TFA. Tetrazine was then added to the dimer $(2.5 \mu \mathrm{mol})$ as described above and the reaction was HPLC purified as described in General Synthetic Methods, affording 1.05 umoles of 8; $0.17 \%$ yield overall. $8\left(\mathrm{C}_{124} \mathrm{H}_{138} \mathrm{~N}_{30} \mathrm{O}{ }_{18}\right)$ calculated mass: $2336.0878(\mathrm{M}+\mathrm{H})$; mass found: $23386.0774(M+H) ; t_{R}=36 \min$.

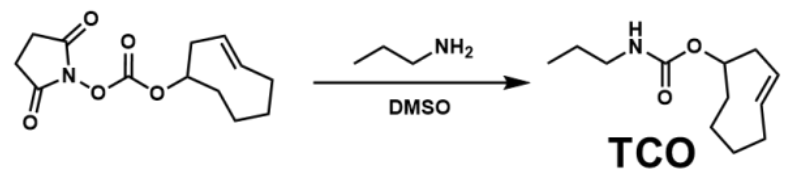

Synthesis of TCO: TCO-NHS ester (Click Chemistry Tools) (4 mg) was reacted with propyl amine (20 equiv) in DMSO $(300 \mu \mathrm{L})$. After the reaction reached completion, as determined by liquid chromatography-mass spectrometry (LC-MS), the reaction mixture was concentrated, resuspended in dichloromethane, filtered through a pad of silica, and used without further purification. Isolated $2.1 \mathrm{mg}, 10 \mu \mathrm{mol}$ of TCO as a clear oil. ${ }_{1} \mathrm{H} \mathrm{NMR}$ (DMSO-d6, $400 \mathrm{MHz}, 25^{\circ} \mathrm{C}$, TMS): $\delta[p p m]=6.95(\mathrm{t}, J=5.5 \mathrm{~Hz}, 1 \mathrm{H} ; \mathrm{NH}), 5.61-5.53(\mathrm{~m}, 1 \mathrm{H} ; \mathrm{CH}), 5.47-5.39(\mathrm{~m}, 1 \mathrm{H} ; \mathrm{CH}), 4.20-4.17$ (m, 1H; CH), 2.92-2.85 (m, 2H; $\left.\mathrm{CH}_{2}\right), 2.30-2.23\left(\mathrm{~m}, 3 \mathrm{H} ; \mathrm{CH}_{2}\right), 1.91-1.84\left(\mathrm{~m}, 4 \mathrm{H} ; \mathrm{CH}_{2}\right), 1.57-1.49(\mathrm{~m}$, 3H; $\mathrm{CH}_{2}$ ), 1.37 (sext., $J=7.2 \mathrm{~Hz}, 2 \mathrm{H} ; \mathrm{CH}_{2}$ ), 0.80 (t, $J=7.4 \mathrm{~Hz}, 3 \mathrm{H}$; $\mathrm{CH}_{3}$ ) ${ }_{13} \mathrm{C}$ NMR (DMSO-d6, 100 $\left.\mathrm{MHz}, 2^{\circ} \mathrm{C}, \mathrm{TMS}\right): \delta=[\mathrm{ppm}] 156.23,135.38,132.99,79.27,42.39,41.18,38.70,34.22,32.63,31.05$ 23.17, 11.71 . 

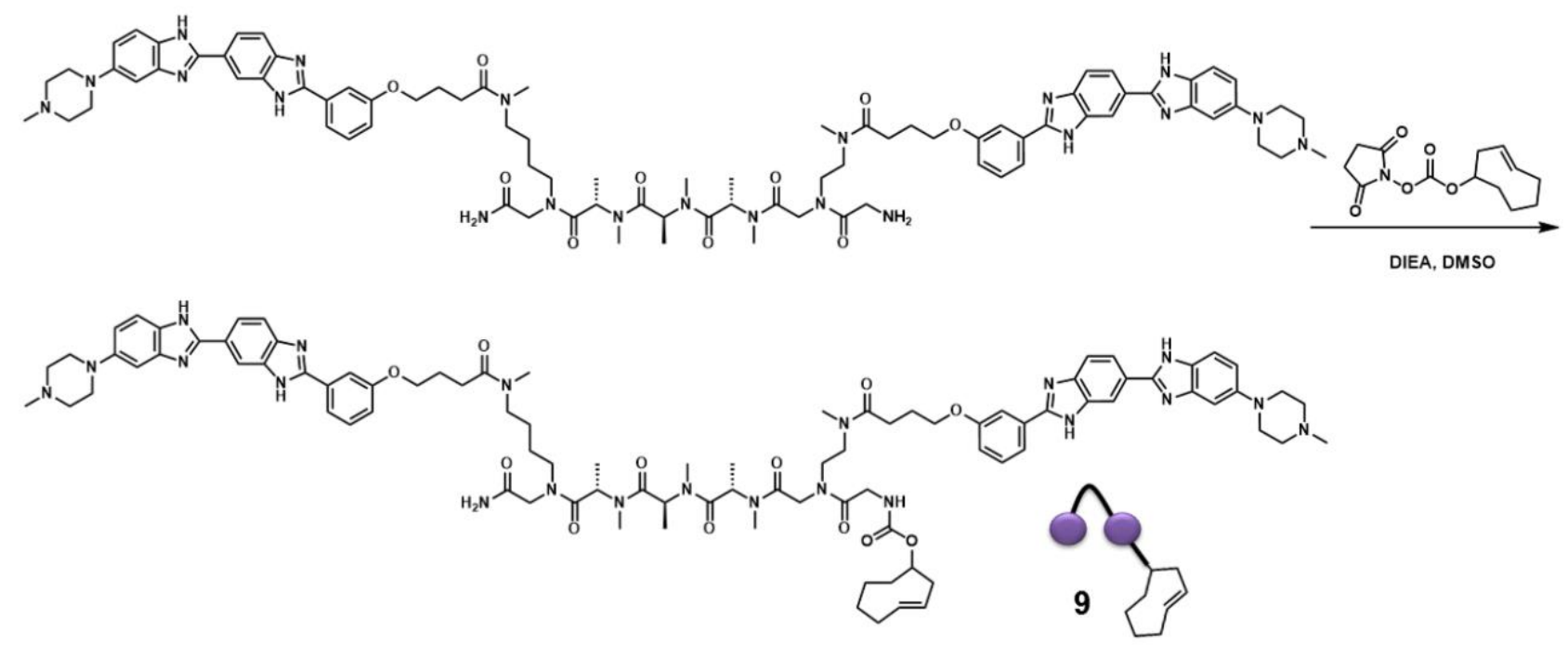

Synthesis of 9: The $2 \mathrm{H}-\mathrm{K} 4 \mathrm{NMeS}$ derivative with a glycine linker was synthesized as previously described.2 TCO-NHS ester (2.7 equiv, $5.95 \mu \mathrm{mol})$ was added to the amine containing dimer (2.2 $\mu \mathrm{mol}$ ) in $200 \mu \mathrm{L}$ DMSO followed by the addition of DIEA (3 equiv). The reaction was stirred at room temperature for $3 \mathrm{~h}$, and then the mixture was purified by HPLC as described in General Synthetic Methods, affording 254 nmoles of $9 ; 11.6 \%$ yield. $9\left(\mathrm{C}_{93} \mathrm{H}_{119} \mathrm{~N}_{21} \mathrm{O}_{12}\right)$ calculated mass: $1722.9420(\mathrm{M}+\mathrm{H})$; mass found: $1722.9380(\mathrm{M}+\mathrm{H}) ; \mathrm{tR}=35 \mathrm{~min}$.

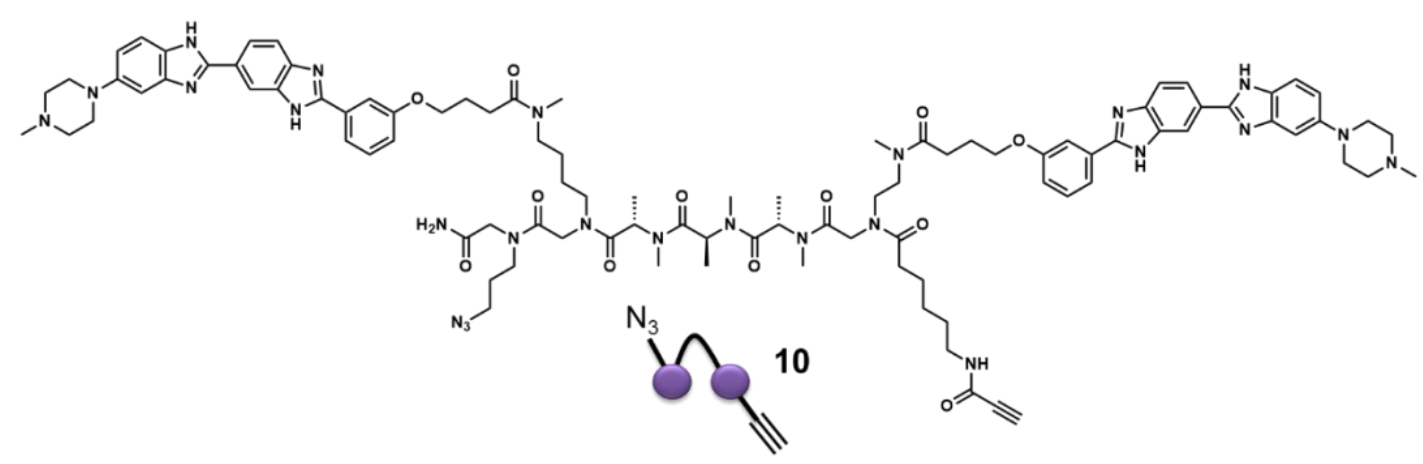

Synthesis of 10: Compound 10 was synthesized as previously described.2 


\section{Characterization of 1.}
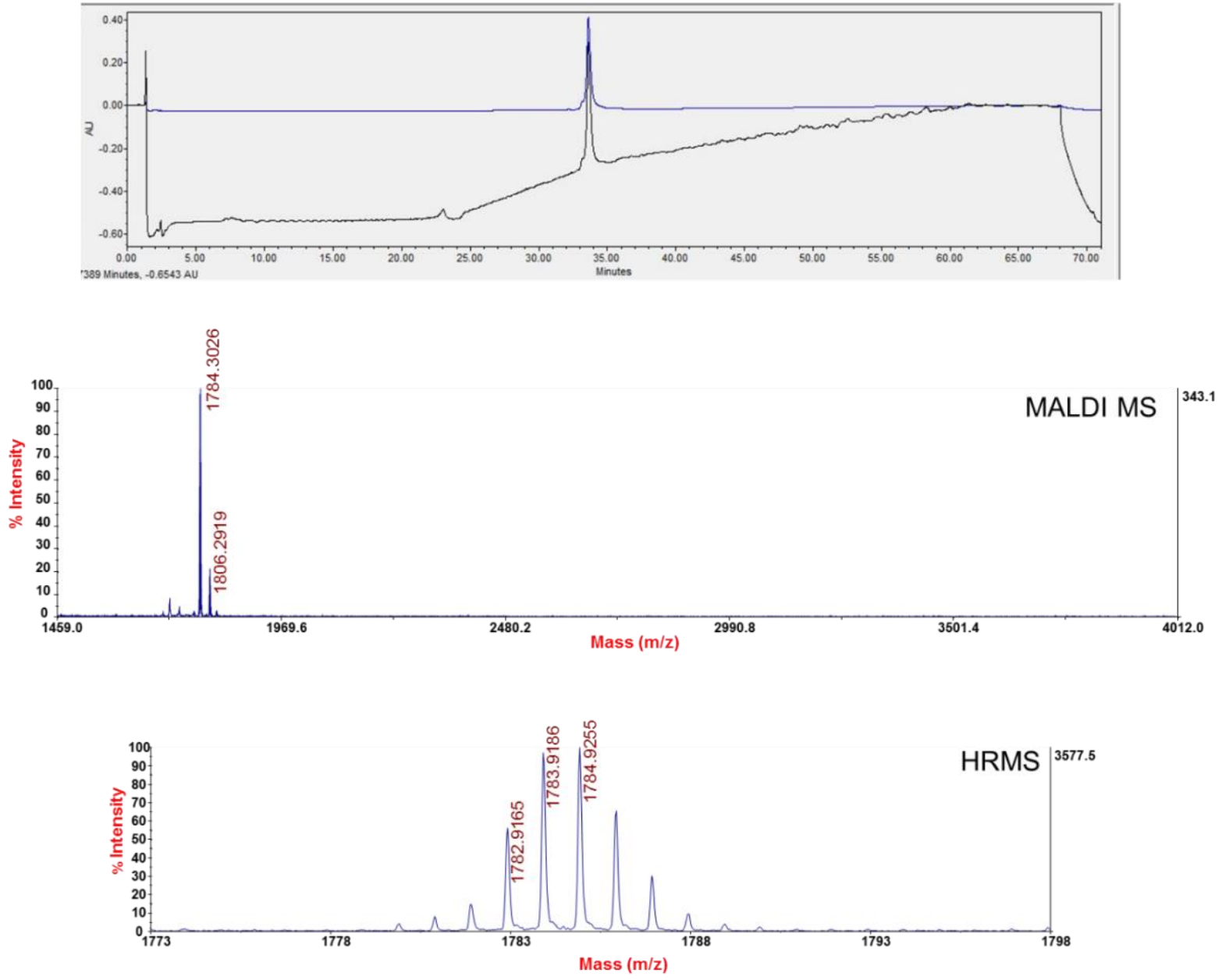


\section{Characterization of 2.}
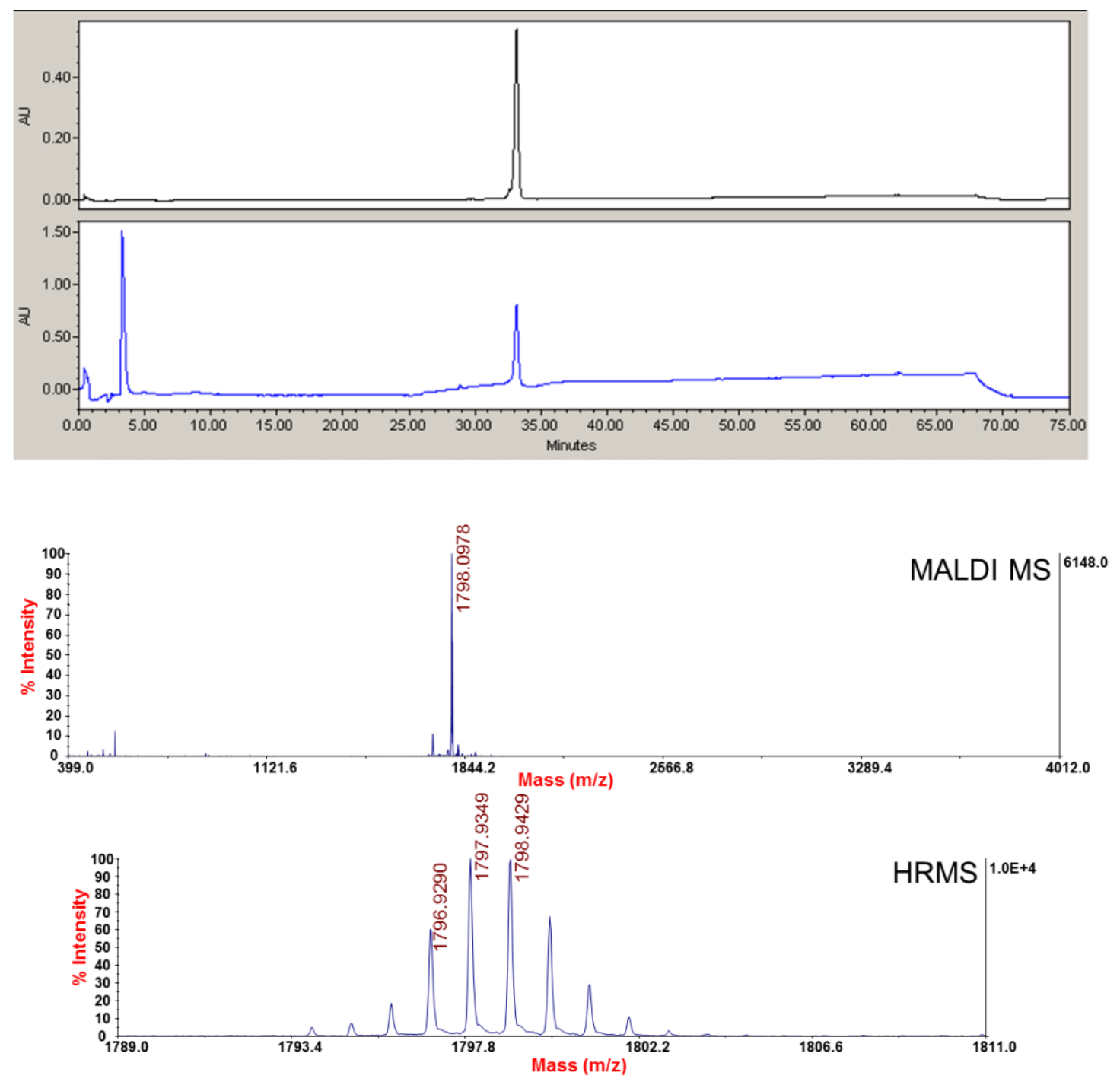


\section{Characterization of 3.}
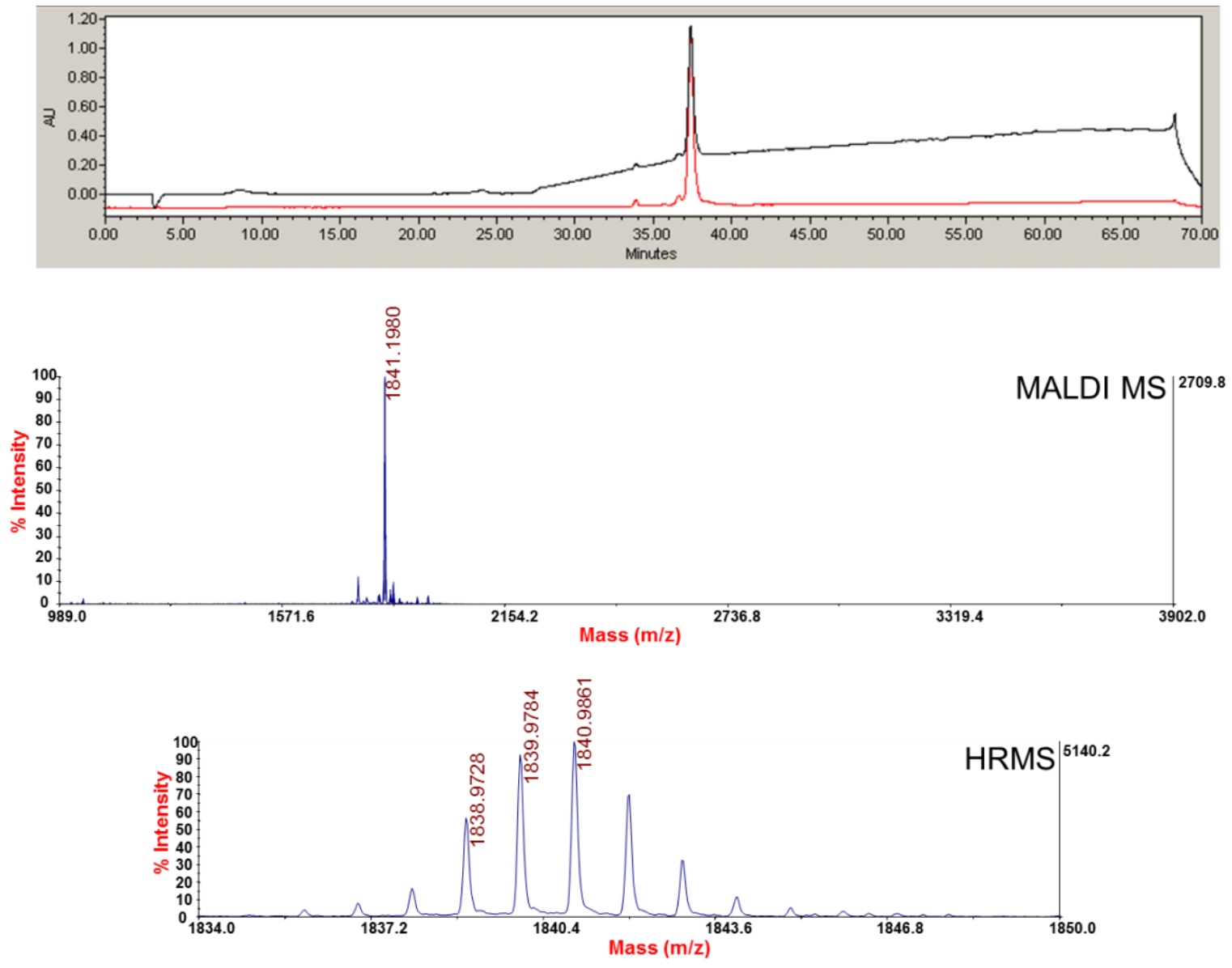


\section{Characterization of 4.}
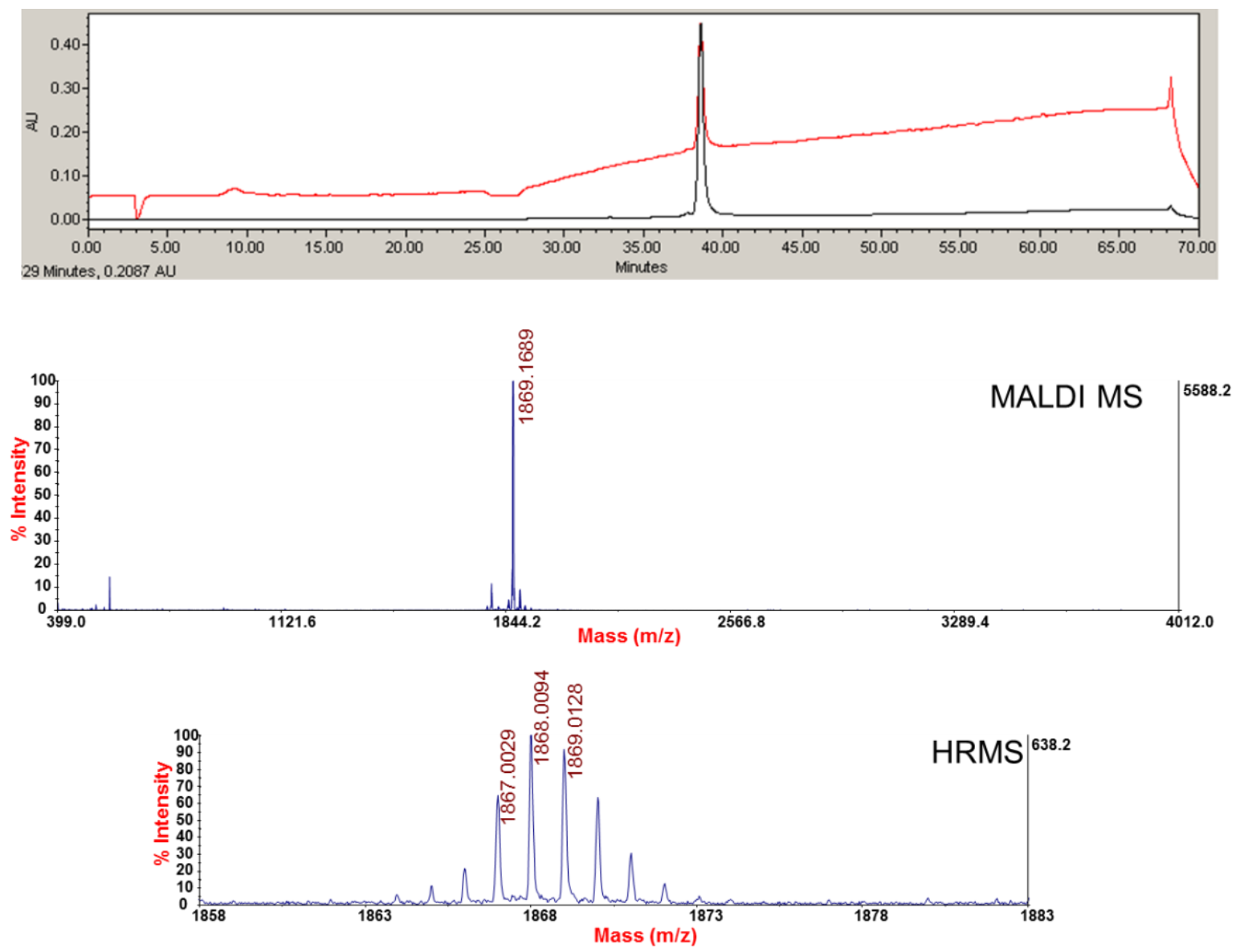


\section{Characterization of 5.}
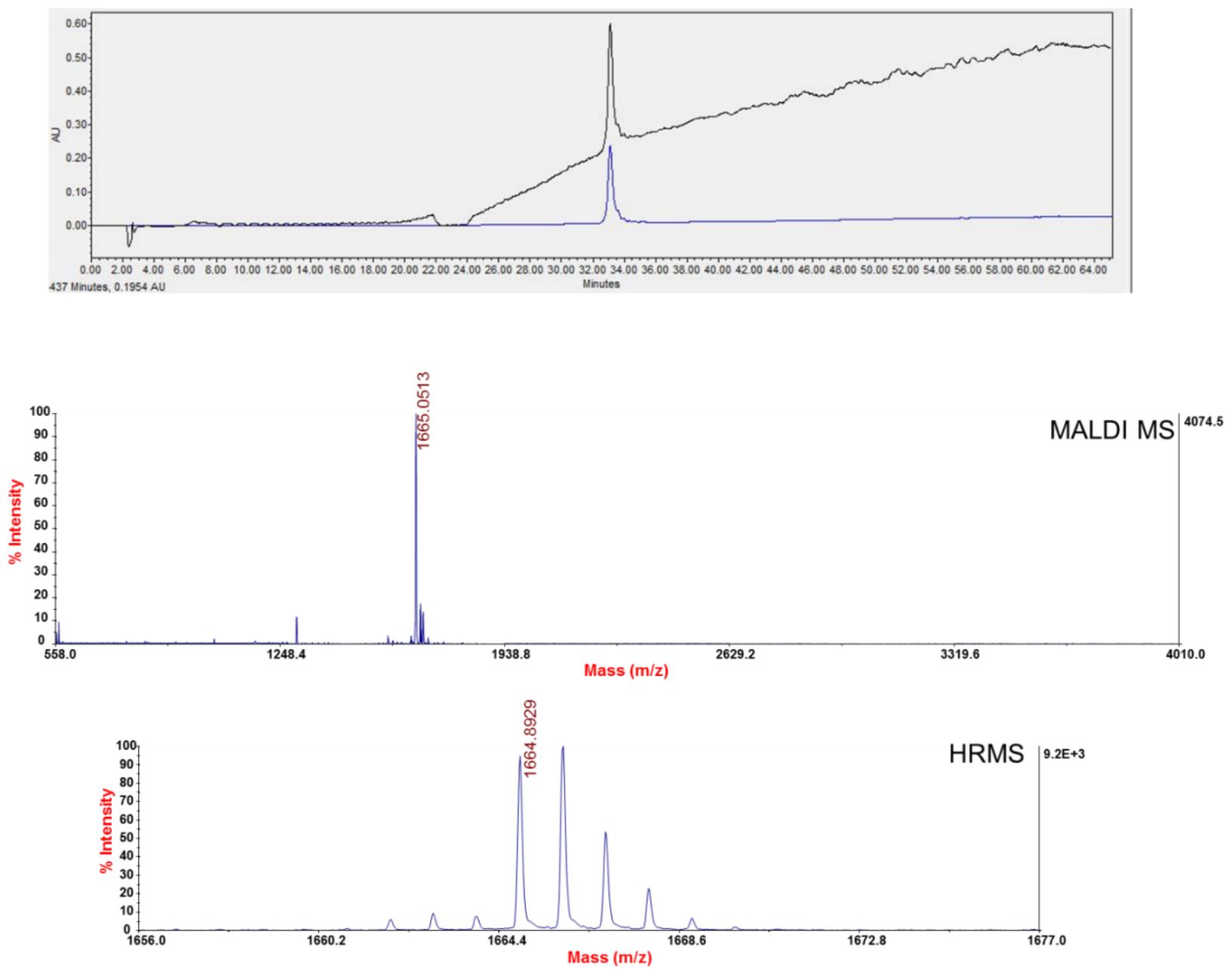


\section{Characterization of 6.}
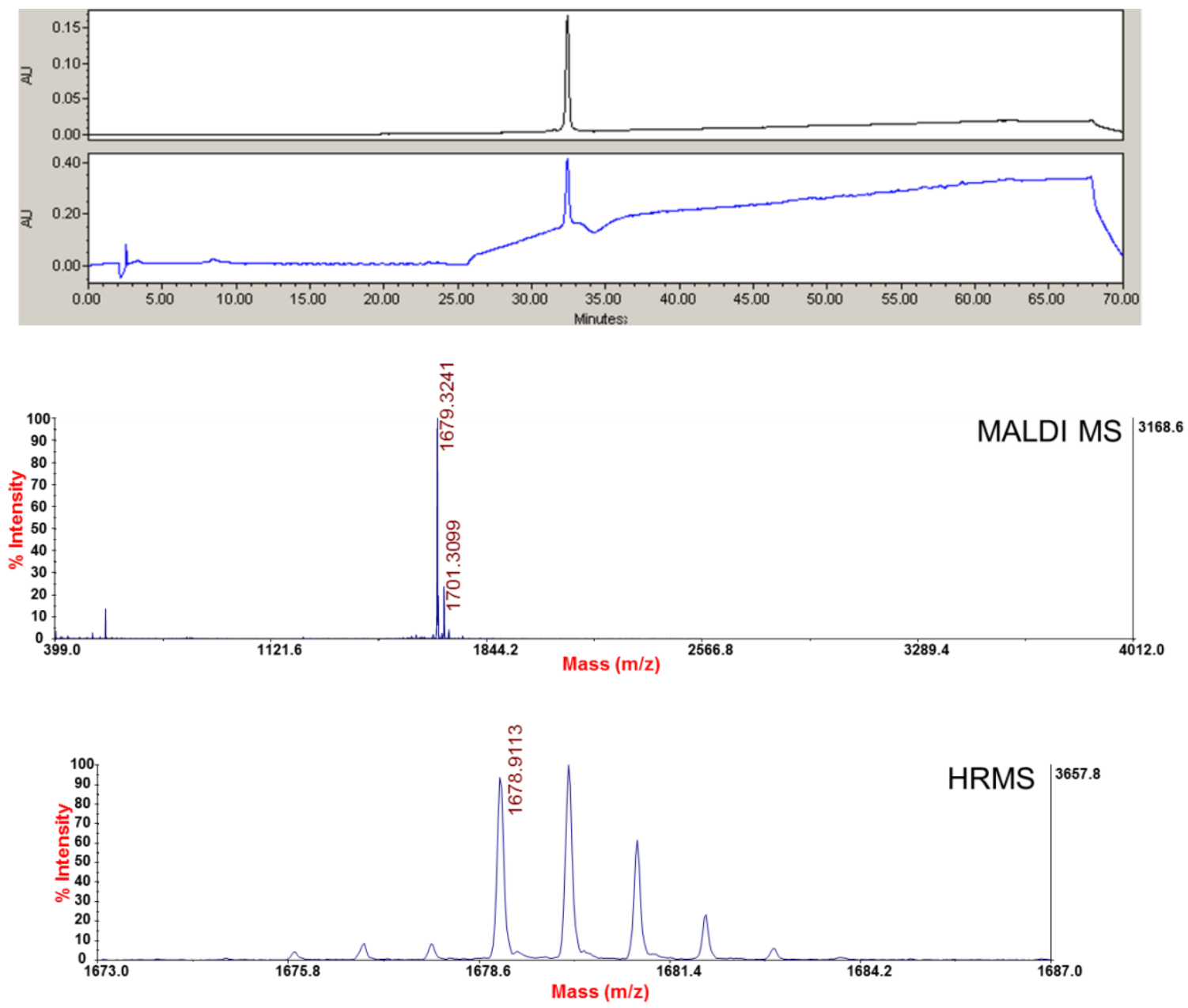


\section{Characterization of Tetramer.}
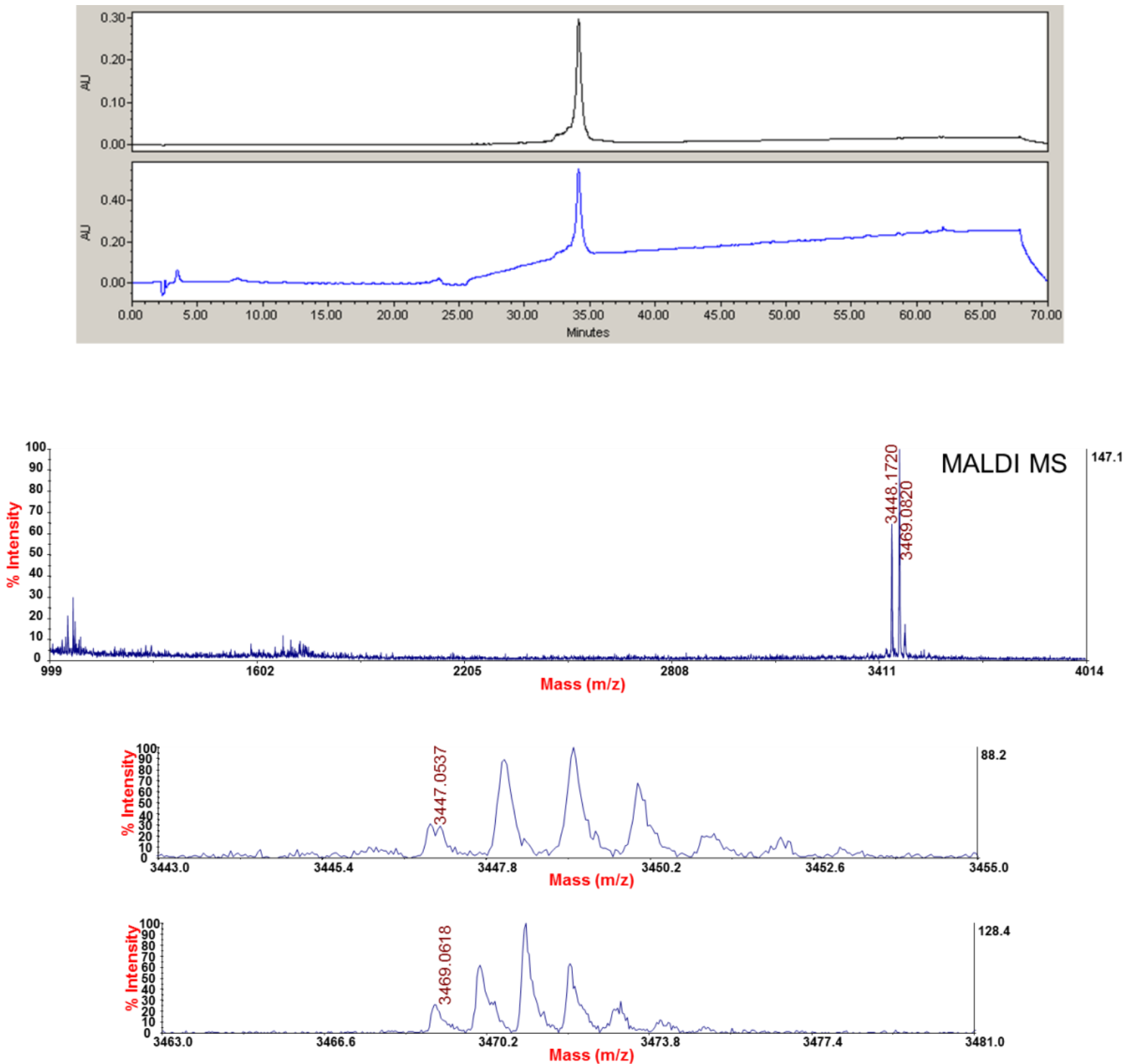


\section{Characterization of 7.}
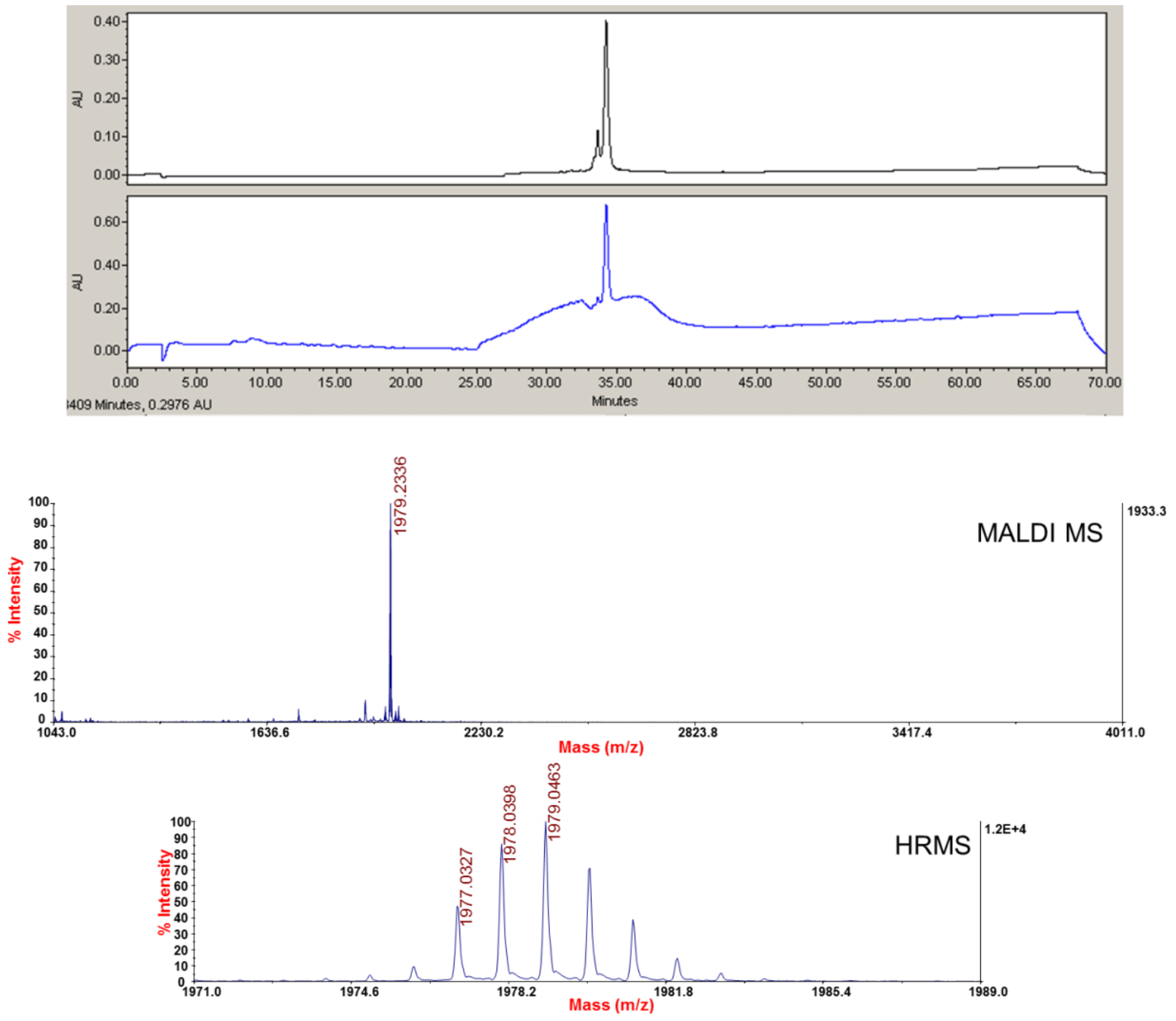


\section{Characterization of 8.}
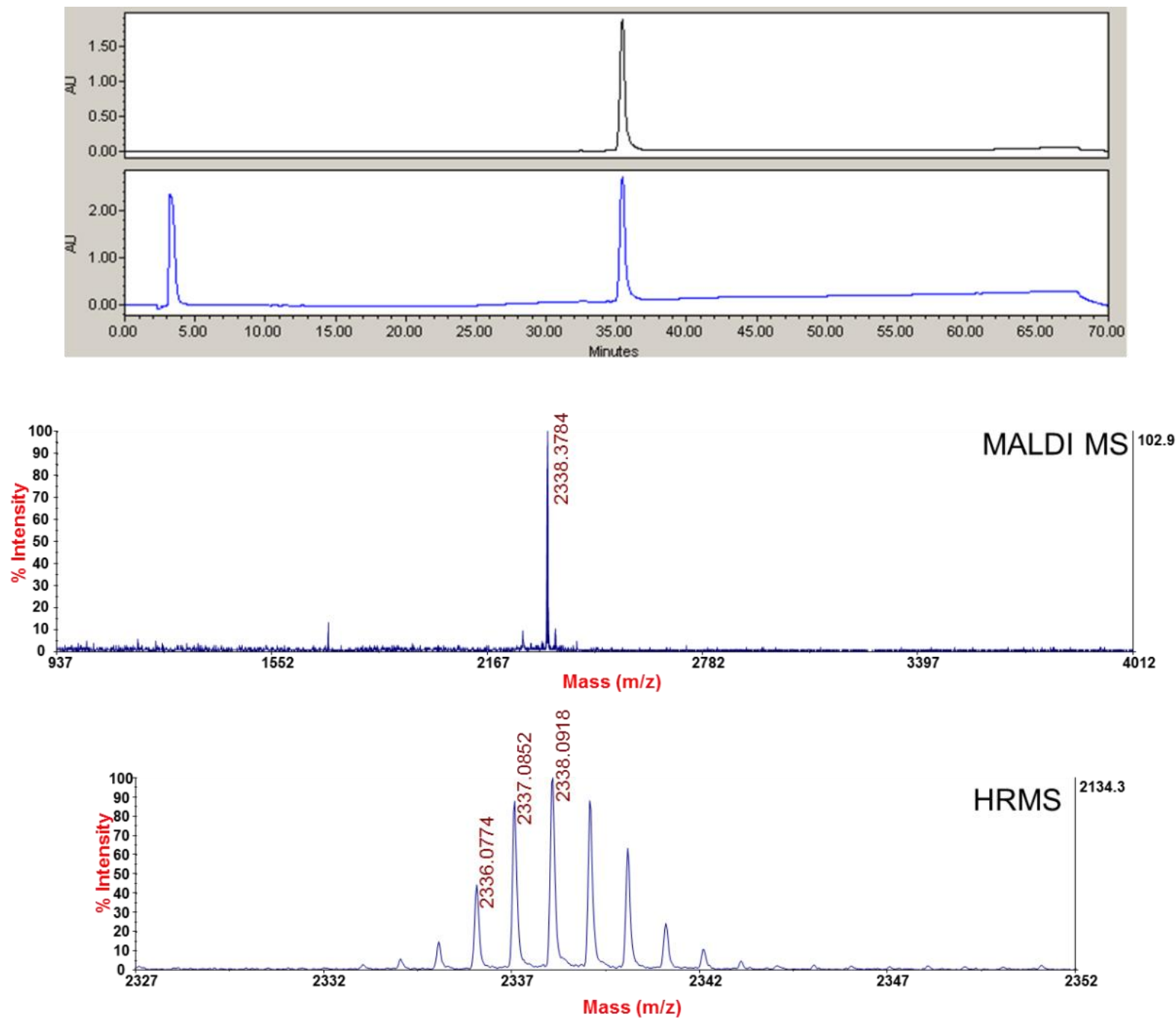


\section{Characterization of 9.}
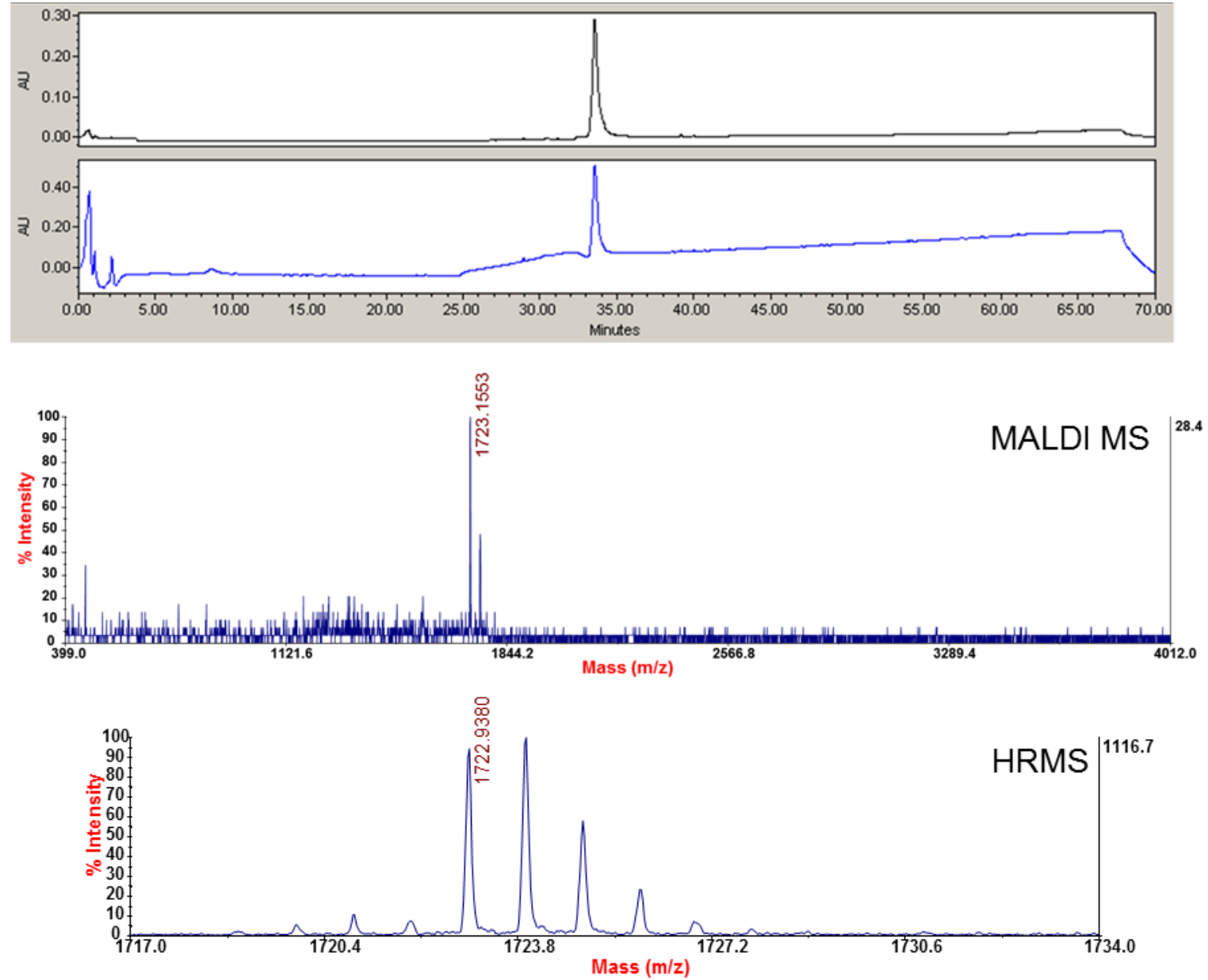
Characterization of TCO.
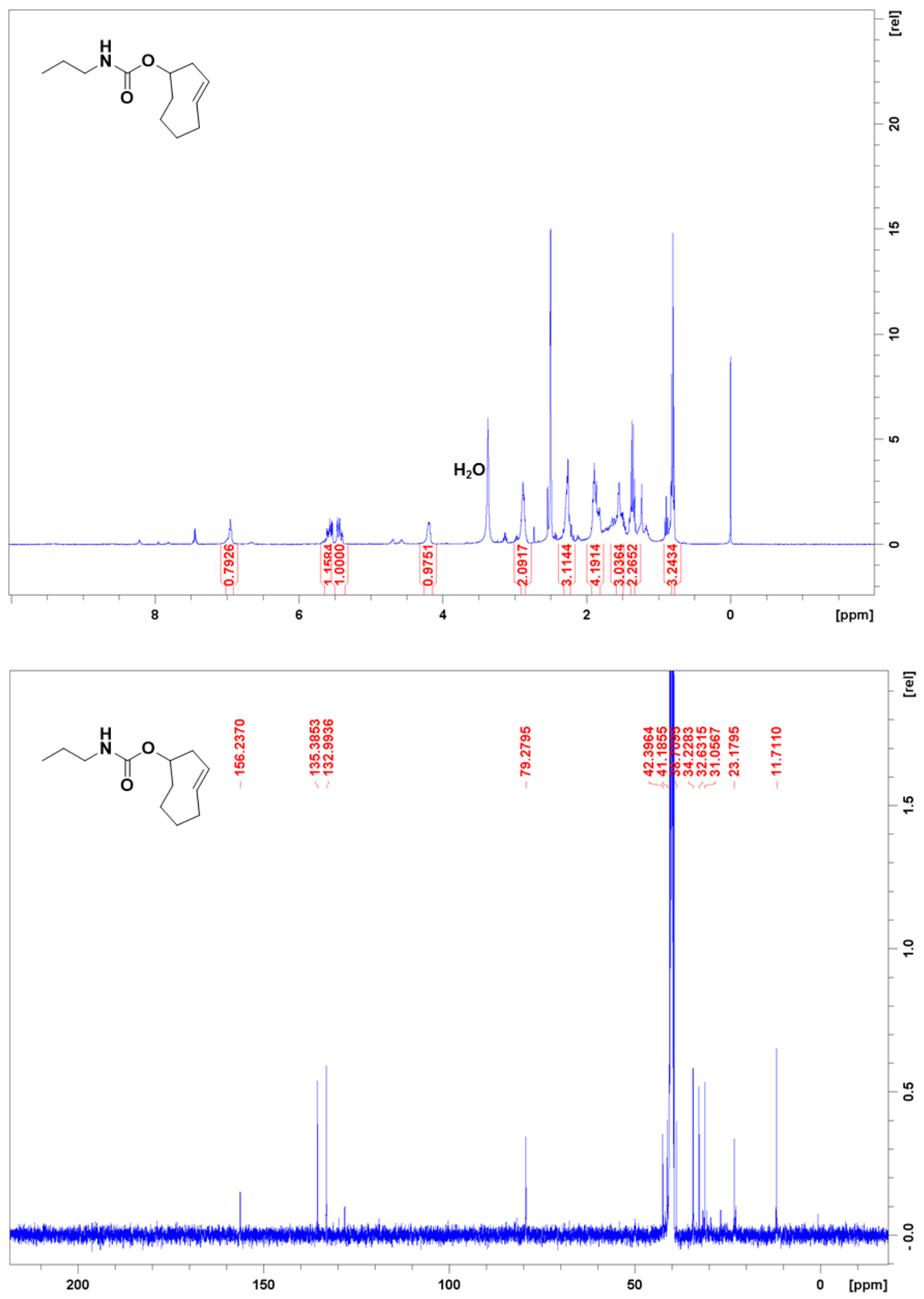


\section{References:}

(1) Au - Pasut, A.; Au - Jones, A. E.; Au - Rudnicki, M. A. Isolation and Culture of Individual Myofibers and their Satellite Cells from Adult Skeletal Muscle. JoVE 2013, e50074.

(2) Rzuczek, S. G.; Colgan, L. A.; Nakai, Y.; Cameron, M. D.; Furling, D.; Yasuda, R.; Disney, M. D. Precise small-molecule recognition of a toxic CUG RNA repeat expansion. Nat. Chem. Biol. 2017, 13, 188-193.

(3) Holt, I.; Mittal, S.; Furling, D.; Butler-Browne, G. S.; David Brook, J.; Morris, G. E. Defective mRNA in myotonic dystrophy accumulates at the periphery of nuclear splicing speckles. Genes Cells 2007, 12, 1035-1048.

(4) Childs-Disney, J. L.; Parkesh, R.; Nakamori, M.; Thornton, C. A.; Disney, M. D. Rational design of bioactive, modularly assembled aminoglycosides targeting the RNA that causes myotonic dystrophy type 1. ACS Chem. Biol. 2012, 7, 1984-1993.

(5) Patterson, D. M.; Nazarova, L. A.; Xie, B.; Kamber, D. N.; Prescher, J. A. Functionalized Cyclopropenes As Bioorthogonal Chemical Reporters. J. Am. Chem. Soc. 2012, 134, 1863818643.

(6) Kulkarni, K.; Motamed, S.; Habila, N.; Perlmutter, P.; Forsythe, J. S.; Aguilar, M.-I.; Del Borgo, M. P. Orthogonal strategy for the synthesis of dual-functionalised $\beta 3$-peptide based hydrogels. Chem. Commun. 2016, 52, 5844-5847.

(7) Pushechnikov, A.; Lee, M. M.; Childs-Disney, J. L.; Sobczak, K.; French, J. M.; Thornton, C. A.; Disney, M. D. Rational design of ligands targeting triplet repeating transcripts that cause RNA dominant disease: application to myotonic muscular dystrophy type 1 and spinocerebellar ataxia type 3. J. Am. Chem. Soc. 2009, 131, 9767-79. 